
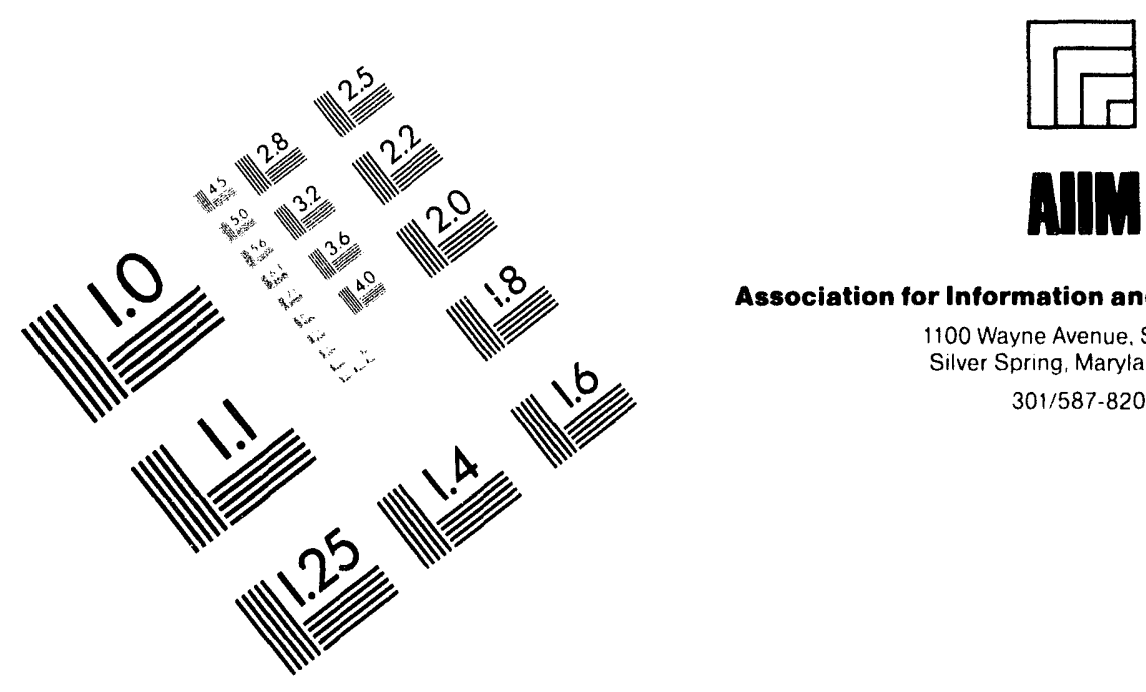

Association for Information and Image Management

1100 Wayne Avenue. Suite 1100

Silver Spring, Maryland 20910

301/587-8202

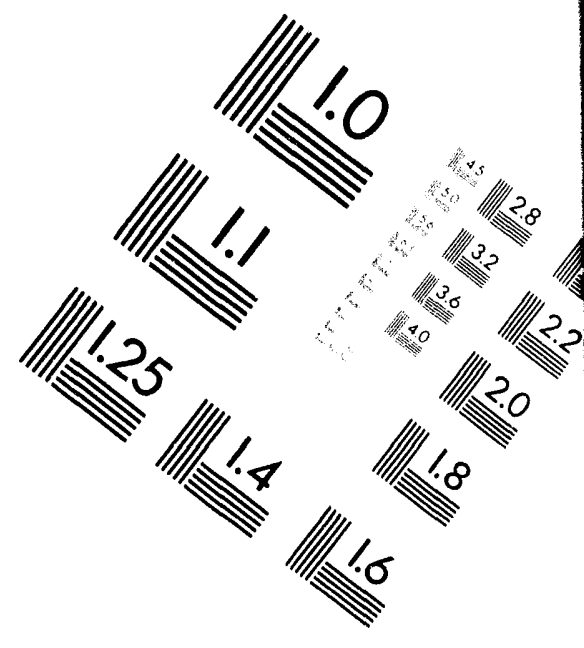

Centimeter

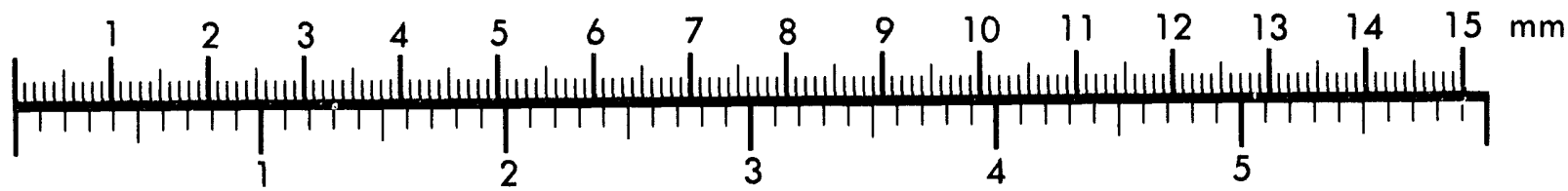
Inches
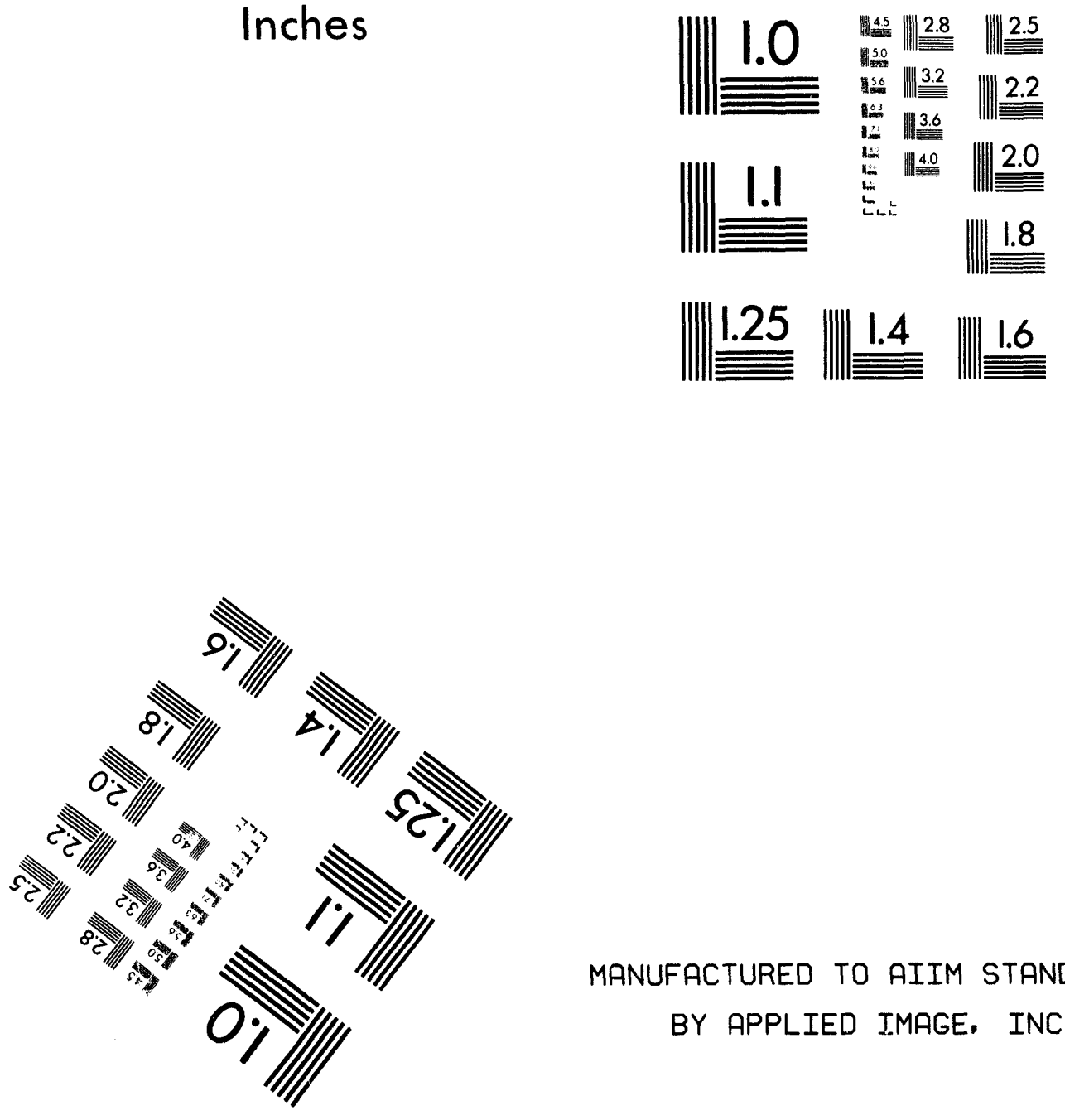

MANUFACTURED TO AIIM STANDARDS

BY APPLIED IMAGE, INC.

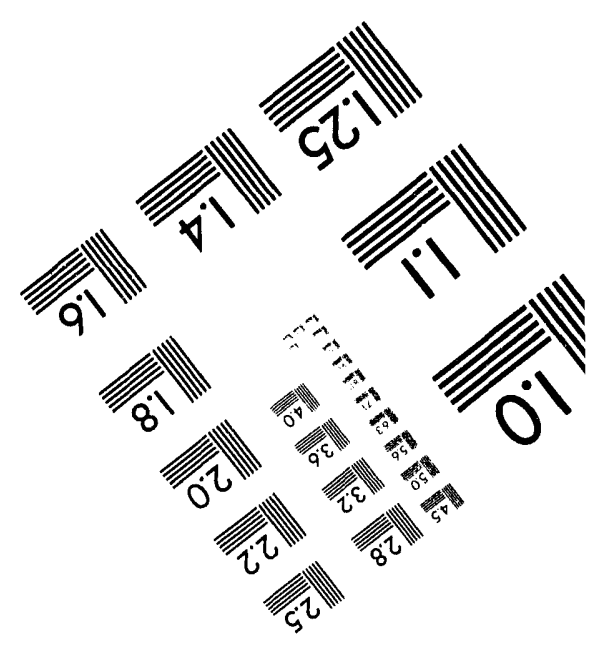



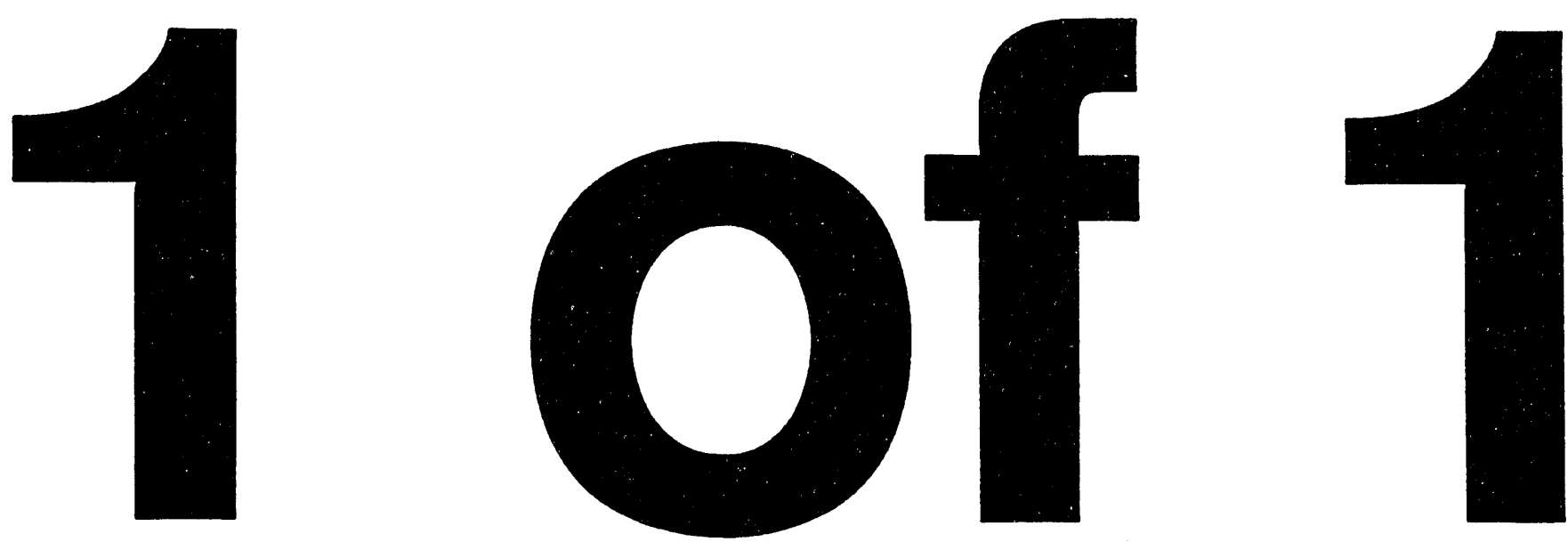


\title{
Evaluation of Population Density and Distribution Criteria in Nuclear Power Plant Siting
}

\author{
Mary Young \\ Accident Analysis and Consequence Assessment Department \\ Sandia National Laboratories \\ Albuquerque, NM 87185-0748
}

\begin{abstract}
The NRC has proposed revisions to 10 CFR 100 which include the codification of nuclear reactor site population density limits to 500 people per square mile, at the siting stage, averaged over any radial distance out to 30 miles, and 1000 people per square mile within the 40-year lifetime of a nuclear plant. This study examined whether there are less restrictive alternative population density and/or distribution criteria which would provide equivalent or better protection to human health in the unlikely event of a nuclear accident. This study did not attempt to directly address the issue of actual population density limits because there are no U.S. risk standards established for the evaluation of population density limits. Calculations were performed using source terms for both a current generation light water reactor (LWR) and an advanced light water reactor (ALWR) design. The results of this study suggest that measures which address the distribution of the population density, including emergency response conditions, could result in lower average individual risks to the public than the proposed guidelines that require controlling average population density. Studies also indicate that an exclusion zone size, determined by emergency response conditions and reactor design (power level and safety features), would better serve to protect public health than a rigid standard applied to all sites.
\end{abstract}

\section{MASTER}




\section{Acknowledgments}

The author thanks Fred Harper, LeAnn Miller, Scott Slezak, and Greg Wyss of Sandia National Laboratories for taking the time on numerous occasions to discuss various aspects of this study. I would also like to thank David Monroe (SNL) and Gregg Wyss for reviewing and refereeing this report. 


\section{Contents}

List of Figures ...........................................................................

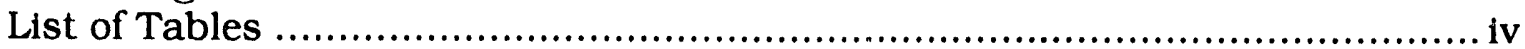

Executive Summary ................................................................

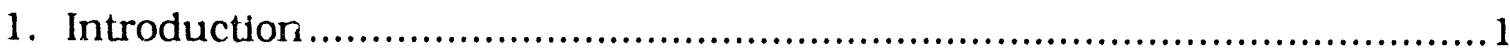

2. Review of Nuclear Reactor Site Population

Density and/or Distribution Studies ............................................

3. Evaluation Approach ...........................................................9

4. Evaluation Results ............................................................... 13

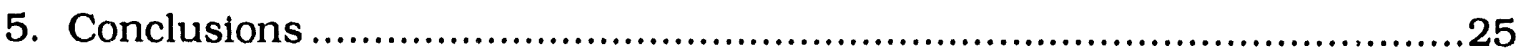

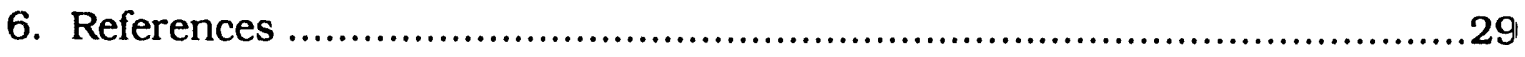

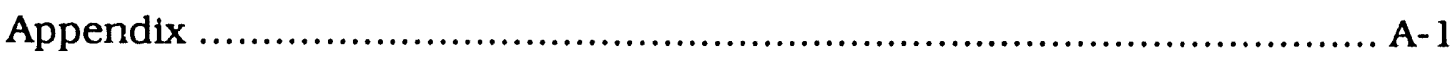

\section{Figures}

1. Aldrich Sudy Population Distributions..........................................5

2. Population Density Distributions Modeled with MACCS ...................... 10

3. LWR Scenario Average Individual Risk of Early Fatalities. ....................14

4. LWR Scenario Average Individual Latent Cancer Risk......................... 14

5. LWR Scenario Normalized Early Fatality Ratio per Interval for the $1.1 \mathrm{~m} / \mathrm{s}$ Evacuation Rate. ................................... 15

6. LWR Scenario Distribution A Early Fatality Ratios for $1.1 \mathrm{~m} / \mathrm{s}$ and $4.8 \mathrm{~m} / \mathrm{s}$ Evacuation Rates.................................... 15

7. LWR Scenario Normalized Cancer Fatality Ratios within the 30 Mile Radius of the Reactor for the $1.1 \mathrm{~m} / \mathrm{s}$ Evacuation Rate. ........ 16

8. LWR Scenario Normalized Cancer Fatality Ratios per Interval................. 17

9. LWR Scenario Total Population Dose within the 30 Miles Radius of the Reactor. ................................................... 17

10. LWR Scenario Mean and 95th Quantile Average Individual Risk of Early Fatalities. ............................................ 18

11. LWR Scenario Mean and 95th Quantile Average Individual Risk of Cancer Fatalities. ............................................. 19

12. LWR Scenario Normalized Early Fatality Ratios for Mean and 95th Quantile Weather Conditions.................................. 19

13. LWR Scenario Normalized Cancer Fatality Ratios for Mean and 95th Quantile Weather Conditions...................................20

14. ALWR Scenario Average Individual Risk of Early Fatalities. .................21 
15. ALWR Scenario Mean and 95th Quantile Average Individual Risk of Early Fatality

16. ALWR Scenario Normalized Early Fatalities for Mean and 95th Quantile Weather Conditions.

17. ALWR Scenario Average Individual Risk of Latent Cancer

18. ALWR Scenario Normalized Total Cancer Fatality Ratio within 30 Miles of the Reactor for the $1.1 \mathrm{~m} / \mathrm{s}$ Evacuation Rate.

19. ALWR Scenario Total Population Dose Within 30 Miles of the Reactor

\section{Tables}

1. Allowable Population Under NRC Proposed Guidelines.........................26

A. 1 Population density per square mile for a sample group of U.S. cities.

A.2 Population density (people per square mile) around U.S. nuclear power plant sites. 


\section{Executive Summary}

The United States Nuclear Regulatory Commission (NRC) has proposed revisions to 10 CFR 100 which include the codification of nuclear reactor site population density limits to 500 people per square mile, at the siting stage, averaged over any radial distance out to 30 miles, and 1000 people per square mile within the 40-year lifetime of a nuclear plant. The proposed revisions also specify the requirement of a 0.4 -mile exclusion zone for new nuclear reactor sites.

This study examined whether there are less restrictive alternative population density and/or distribution criteria which would provide equivalent or better protection to human health in the unlikely event of a nuclear accident. This study also examined whether 30 miles is a reasonable radius within which to control population density around nuclear plant sites based on human health consequences and the influence of the rate of evacuation on the resultant health consequences.

The proposed population density criteria limit population density only in terms of average population. The maximum population is specified for any radius out to 30 miles, but the distribution of the $\mathrm{F}$ spulation within the radius is not specified. Under the proposed rule, sites would be rated equally whether this population is uniformly distributed within the 10-mile radius, or distributed primarily in the areas at the greatest distance from the reactor.

This study did not attempt to directly address the issue of actual population density limits because there are no clear U.S. standards established for the evaluation of population density limits. The quantitative health objectives (QHOs) developed by the NRC to quantify the qualitative NRC Safety Goals define a level of acceptable radiological risk in terms of average individual risk, but average individual risk is (by definition) not a function of population density. For a specific accident scenario and pattern of relative population distribution, average individual risk will remain constant as population density increases or decreases although the actual affected population will scale linearly with increases in population density.

The MELCOR Accident Consequence Code System (MACCS) version 1.5.11.1 [Ref. 6.4] was utilized for the analysis of the health consequences of a severe accident release to four hypothetical population distributions. The distributions were designed to be consistent with the proposed population density guidelines in order to evaluate the technical merits of the guidelines.

Calculations were performed using source terms for both a current generation light water reactor (LWR) and an advanced light water reactor (ALWR) design. Both source terms were severe accident source terms calculated to have a frequency of approximately $1 \times 10^{-8}$ per reactor year. These severe accident source terms are highly improbable events and were not chosen to represent likely nuclear accident scenarios or to test compliance with the safety goals. 
but rather to generate accident scenarios which would clearly illustrate the effects of different population distributions on potential accident consequences.

The results of this study indicate that the levels of average individual risk of fatality typically decrease as distance from the reactor increases.

Subsequently, the magnitude of the population density relative to the distance from the reactor can significantly effect the level of human health consequences resulting from a severe accident. Beyond 10 miles from the reactor for the LWR scenario and beyond 1.3 miles for the ALWR scenario the average indiridual risk of early fatality is zero. The LWR scenario average individual risk of early fatality for the $1.1-\mathrm{m} / \mathrm{s}$ evacuation rate decreased by two orders of magnitude between 0.4 mile to 3.5 miles from the reactor. The ALWR scenario average individual risk of early fatality decreases by four orders of magnitude between the 0.4 and 1.3 mile radius from the reactor for both the evacuation and no evacuation scenario.

The LWR scenario maximum average individual risk from latent cancers for the $1.1-\mathrm{m} / \mathrm{s}$ evacuation rate occured between 1.3 miles and 2.0 miles from the reactor. The $L W R$ scenario latent cancer risk for the $1.1-\mathrm{m} / \mathrm{s}$ evacuation rate decreased by approximately an order of magnitude between 0.4-mile to 10.0 miles from the reactor. The average individual risk of latent cancer for the ALWR scenario did not decrease with distance as significantly as the LWR scenario, however, the maximum average individual risk of latent cancer was more than an order of magnitude higher for the LWR than for the ALWR scenario. The reduction in the average individual risk of latent cancer for the ALWR scenario as the distance from the reactor increased to 30 miles was less than an order-of-magnitude. The average individual risk of latent cancer for the ALWR scenario was highest in the interval nearest the reactor.

The results of this study also indicate that evacuation rates can affect the average individual risk estimates within a 5-mile radius of the reactor but that the magnitude of this eifect is dependent on the source term. The LWR scenario results indicate that evacuation is most important when the population density is relatively high close to the facility. The increase in the evacuation rate has little effect on the average individual risk values for the ALWR scenario. However, the ALWR scenario which assumed no evacuation, had an average individual risk of early fatality one order of magnitude higher than the evacuation scenarios.

Findings prior to this study [Aldrich et al, Ref 6.2], indicated that large exclusion zones without emergency response (e.g., evacuation) are not nearly as effective as a substantially smaller exclusion zone and a timely emergency response. However, because early health effects are usually confined to only a few miles, exclusion zones can have a substantial impact even without an emergency response.

The proposed population density guidelines limit the total population within the 30 mile radius surrounding a reactor. The proposed population density guidelines would subsequently serve to limit the total human health consequences and the interdiction costs resulting from a severe accident. 
The results of this study; however, indicate that there may be alternatives to the proposed population density guidelines which would provide equivalent or better protection to human health in the event of a nuclear accident.

Potential health risks to the population typically decrease as distance from the reactor increases and the highest risk to the population is within the first 10 miles of the reactor. Guidelines which would address the actual distribution of the population in the vicinity of the plant rather than the average population density could have a quantitative effect on the calculated risks. Estimated evacuation rates, dependent upon the local population distribution and available evacuation routes, have also been demonstrated to affect the calculated accident human health consequences and are therefore important parameters to be included in piant site selection.

A review of policies abroad applicable to the establishment of maximum population density limits within any radius of a hazardous facility indicates that the Dutch and Hong Kong governments have institutionalized policies which define levels of acceptable and unacceptable risk as functions of the potential number of fatalities and the probability of the event. The U.S. NRC QHO's specify only a maximum level of acceptable risk which is not dependent on population density. The QHOs of the Safety Goals therefore do not provide a basis or rationale for the regulatory restrictions of population density in the vicinity of nuclear reactors. Although population density limits cannot be developed from the U.S. NRC QHOs, the results of this study suggest that measures which address the distribution of the population density, including emergency response conditions, could result in lower average individual risks to the public than the proposed guidelines that require controlling average population density. Studies also indicate that an exclusion zone size, determined by emergency response conditions and reactor design (power level and safety features), would better serve to protect public health than a rigid standard applied to all sites. 


\section{Introduction}

The U.S. Nuclear Regulatory Cominission (NRC) has proposed revisions to 10 CFR 100 which include the codification of nuclear reactor site population density limits to 500 people prr square mile, at the siting stage, averaged over any radial distance out to 30 miles, and 1000 people per square mile within the 40-year lifetime of a nuclear plant." The proposed revisions also specify the requirement of a 0.4 -mile exclusion zone for new nuclear reactor sites. The NRC consideration for the specification of population density limits to a radius of 30 miles from the plant is the possibility of land contamination out to 30 miles in the event of a severe accident sufficient to require the long-term condemnation of land IU.S. NRC, 1992].

The proposed population density criterla limit population density only in terms of average population. The maximum population is specified for any radius out to 30 miles, but the distribution of the popuiation within the radius is not specified. For example, the 500-people-per-square mile density limit allows a population of 156,828 within the 10 -mile radius of the reactor. Under the proposed rule, sites would be rated equally whether this population is uniformly distributed within the 10 -mile radius, or distributed primarily in the areas at the greatest distance from the reactor.

This study examined the calculated heaith effects for various population distributions in the vicinity of a typical light-water reactor (LWR) plant of the type currently operating, as well as a proposed advanced light water reactor (ALWR) design.

This study did not attiempt to directly address the issue of actual population density limits because there are no clear standards established for the evaluation of population density limits. Although the NRC Safety Goals define a level of acceptable radiological risk, these goals cannot be utilized to derive population density limits. The quantitative health objectives (QHOs) developed by the NRC to quantify the qualitative safety goals are defined as follows IU.S. NRC, 1989]:

- The risk of an early fatality to an average individual within one mile of the reactor security fence should be less than $5 \times 10^{-7}$ per year.

- The risk of long-term (latent cancer) fatality to the workers and the general public located within 10 miles of the reactor facility control perimeter should be less than $2 \times 10^{-6}$ per average individual per year.

The NRC has specified the use of mean estimates of average individual risk for implementing the quantitative health objectives [U.S. NRC, 1986]. Average

\footnotetext{
* According to 1990 census data, there are ten sites with currently operating nuclear reactors which would not meet the proposed criteria. See Appendix A for additional comparison population density information.
} 
individual risk is the sum of the risks incurred by the population within a region divided by the number of individuals in the regton (Helton and Breeding, 1992]. The average individual risk for a specific accident scenario and patterri of relative population distribution will remain constant as population density increases or decreases although the actual number of affected individuals will be linearly proportional to density. Metrics which can be used for the representation of accident health consequences as they vary with population density are estimates of total population dose and total prompt and latent fatalities.

Another issue in utilizing the NRC Safety Goals for the evaluation of the proposed population density limits is that the safety goals are defined only to the 10 -mile radius from the reactor. The NRC has provided the following justification for the Safety Goal specification of latent cancer risk only within 10 miles of reactor sites [U.S. NRC, 1986]:

The distance for averaging the cancer fatality risk was taken as 50 miles in the 1983 policy statement. The change to 10 miles could be viewed to provide additional protection to individuals in the vicinity of the plant, although analyses indicate that this objective for cancer fatality will not be the controlling one. It also provides more representative societal protection, since the risk to the people beyond 10 miles will be less than the risk to people within 10 miles.

Although the average individual risk values cannot be used to evaluate population density issues, they are a useful representation of a general level of population health risk. They can also be utilized as a metiic by which to evaluate other siting parameters such as emergency response scenarios. 


\section{Review of Nuclear Reactor Site Population Density and/or Distribution Studies}

In the early 1980s, a comprehensive study was conducted by Aldrich et al. to evaluate nuclear power plant siting criteria [Aldrich et al., 1982]. Reactor accident-consequences for this study were calculated using the CIRAC2 computer software code. The effort included sensitivity studies to evaluate the potential effect of population distribution and density on the human health consequences of a nuclear accident. The study initially modeled all 91 U.S. reactor sites assuming a representative meteorological record, a standard $1120-$ MWe reactor, and a SST1 release. Early fatalities, early injuries, and latent cancer fatalities were calculated. The range of the mean early fatalities for the 91 reactor sites was 0.4 to $970: 4$ to 3600 for early injuries and 230 to 8100 for latent cancer fatalities. The wide variability in the calculated distributions can be attributed only to differences in the density and the distribution of the population at the 91 sites because all other factors (meteorology, source terms, einergency response scenario) were held constant.

The different degrees of variability between the estimated early fatalities, early injuries, and latent cancers are primarily due to the different distances to which each consequence occurs; i.e., there is less variability in the latent cancer estimates than in the early fatality estimates because this health consequence occurs at higher distances from the plant where there is less variation in the population density between plant sites. This analysis also indicated that the effective implementation of emergency protective actions in areas near the reactor could result in substantial reductions in distances to which fatal or injury-causing doses of radiation could be received.

The Aldrich study also indicated that accident-consequence calculations out to the 99 th percentile were only marginally impacted by site-specific meteorology. This finding indicates that site-specific weather is not a critical parameter for accident-consequence calculations. However, the variation in the 99th percentile results indicated that site-specific weather, particularly sites with a high frequency of precipitation, can significantly increase accidentconsequences under worst-case weather conditions.

To further understand the effects of population distribution on accidentconsequences, accident-consequence analyses were completed on nine hypothetical population distributions developed for the Aldrich study. The nine distributions were developed to better define the sensitivity of early fatalities and injuries to the following features of population distributions:

\footnotetext{
- An SST1 release represents severe core damage. It essentially involves loss of all installed safety features and a severe direct breech of containment. The probability of an SST 1 release was estimated as $10^{-5} /$ reactor year. [Aldrich et al., 1982]
} 
- Radial and angular variations in population density.

- The size and distance of population centers.

- Exclusion zone size.

Figure 1 reviews the nine distributions studied, including mean early fatality and mean early injury data. The distributions are numbered in terms of increasing mean early fatality numbers; i.e., distribution 1 has the lowest mean early fatality, distribution 9 has the highest mean early fatality number. Distribution 6, a uniform population distribution of 750 people per square mile, was considered the reference distribution. The characteristics of these distributions were the following:

- Each distribution had 940,000 people within 17 miles of the reactor.

- For all nine distributions, within 5, 10, 15, 20, and 30 miles of the reactor, the average population density was either zero or 750 people per square mile.

- Each distribution had a uniform population of 750 people per square mile from 20 to 30 miles.

- None of the distributions had people within 0.5 mile of the reactor.

- Distributions 8, 4, 2, 3, and 1 moved all of the population within 2, 5 . 10,15 , and 20 miles, respectively, into single 22.5-degree sectors toward the outer radius of the vacated regions.

The results presented in Figure 1 suggest that the recommended population density criteria may not address the key population density/distribution variables which have the greatest impact on the potential health consequences of nuclear accidents. The three distributions with the fewest mean early fatalities, distributions 1,2 , and 3, had major population centers within 17 miles of the reactor, but also had their populations distributed primarily in the outer area of the 20-mile radius around the reactor. Although all of the distributions had an average population density of 750 per square mile within the 20-mile radius, Distribution 8 had more than 5 times the mean early fatalities of Distribution 1. The distributions with the highest mean early fatality and injury numbers had their population distributed closer to the reactor site. Distribution 9 , with the highest mean early fatalities and injuries, cannot be legitimately compared to the proposed population density criteria because the distribution was constructed by moving the reference distribution population within 20 miles forward into 5 high-density rings. The proposed criteria, 500/1000 people per square mile out to 30 miles, limit the average population density averaged out to any radial distance.

Additional information is obtained regarding potential accident-consequences by examining the 99 th percentile results presented for the distributions. The 99th percentile results represent the accident-consequences resulting from worst-case weather conditions. These results indicate that populations concentrated within one area (rather than evenly distributed around a plant) have lower mean risk values but significantly higher worst-case consequence 


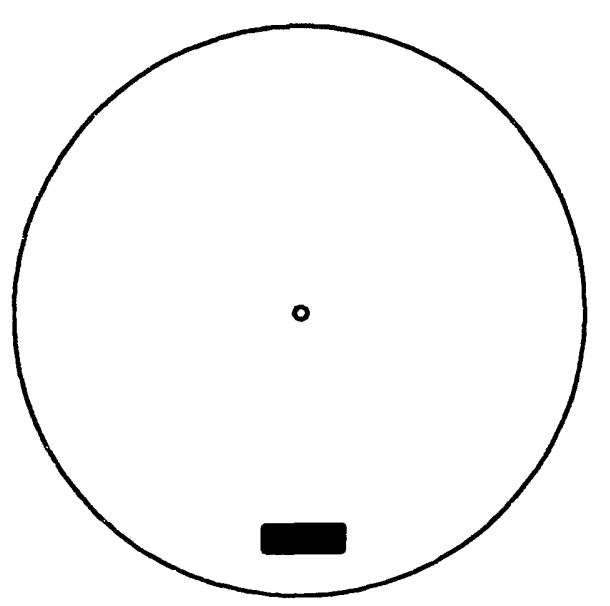

\section{Distribution 1}

City of $940,00016.25$ miles out

$\mathrm{EF}_{\mathrm{m}}=110 \quad \mathrm{EI}_{\mathrm{m}}=1.2 \mathrm{e} 3$

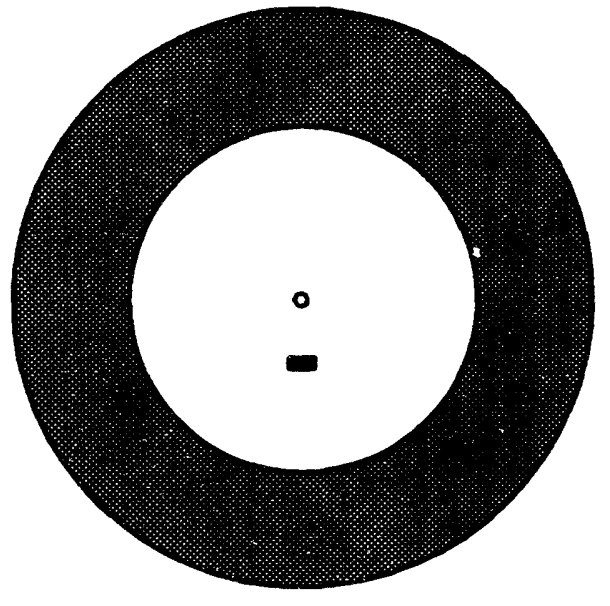

Distribution 2

City of 232,000 6.75 miles out

$\mathrm{EF}_{\mathrm{m}}=110 \quad \mathrm{EI}_{\mathrm{m}}=1.5 \mathrm{e} 3$

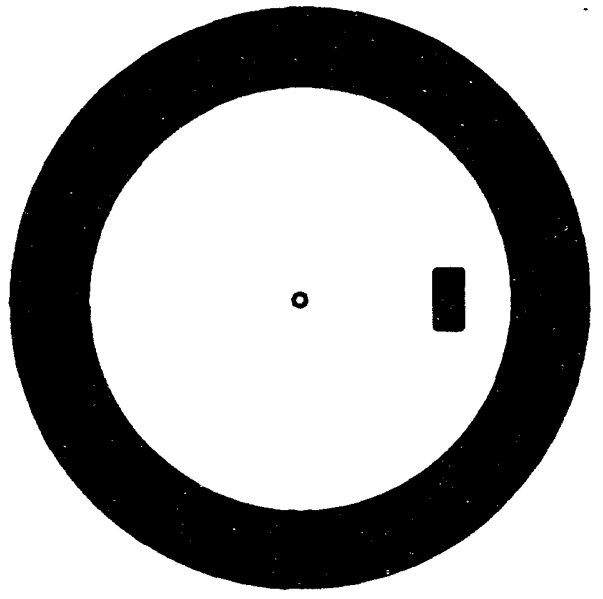

Distribution 3

City of 527,000 12.5 miles out

$\mathrm{EF}_{\mathrm{m}}=160 \quad \mathrm{EI}_{\mathrm{m}}=1.9 \mathrm{e} 3$

Figure 1. Aldrich study population distributions. Mean early fatalities (EF $m$ ) and mean early injuries (EIm) for population distributions assuming SS1 release, a 1120 MWe reactor, summary evacuation, New York City Meteorology, and a uniform wind rose. All nine distributions contain 939,000 people within 20 miles of the reactor. 


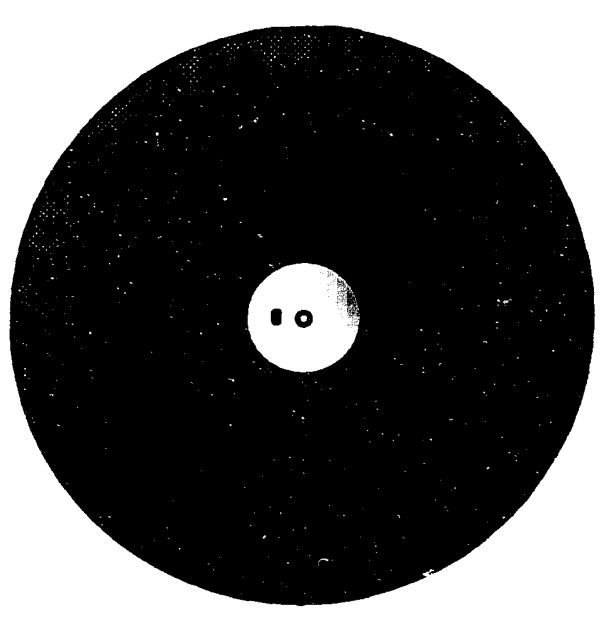

Distribution 4

City of 55,800 3 miles out

$\mathrm{EF}_{\mathrm{m}}=250 \mathrm{EI}_{\mathrm{m}}=2.2 \mathrm{e} 3$

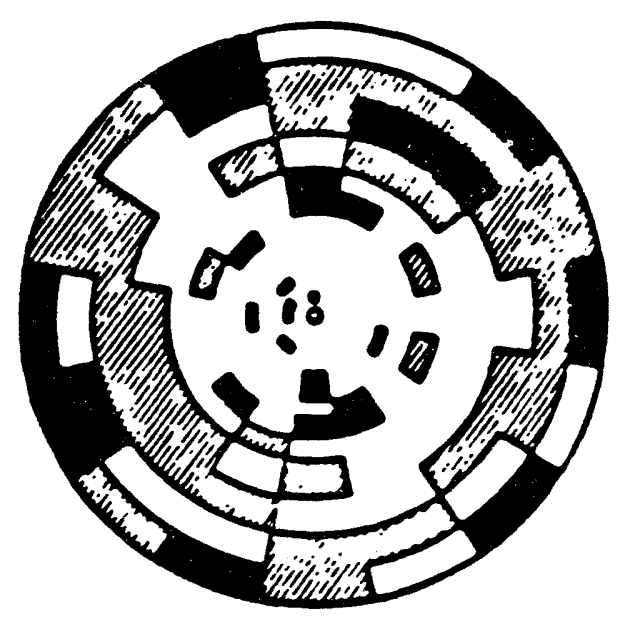

Distribution 5

Actual 1980 Distribution (scaled)

$\mathrm{EF}_{\mathrm{m}}=260 \mathrm{EI}_{\mathrm{m}}=1.8 \mathrm{e} 3$

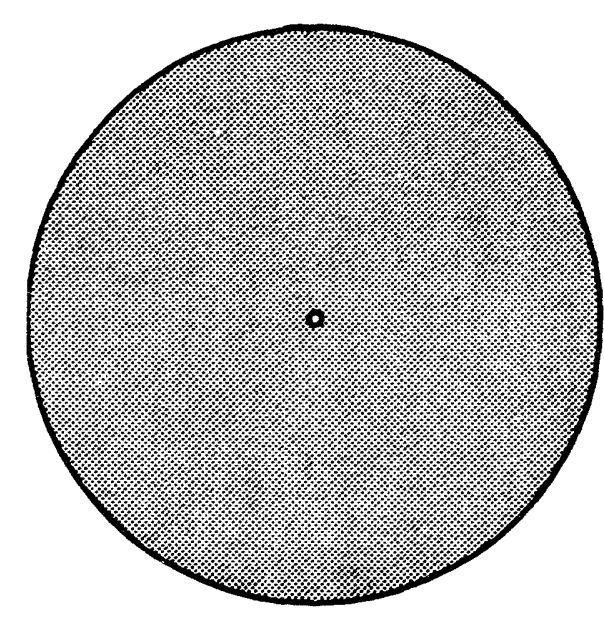

Distribution 6

Uniform population distribution

$\mathrm{EF}_{\mathrm{m}}=400 \quad \mathrm{EI}_{\mathrm{m}}=2.2 \mathrm{e} 3$

Figure 1 (con't). Ndrich study population distributions. Mean early fatalities (EF $m$ ) and mean early injuries $\left(\mathrm{EI}_{\mathrm{m}}\right)$ for population distributions assuming SS1 release, a 1120 MWe reactor, summary evacuation, New York City Meteorology, and a uniform wind rose. All nine distributions contain 939,000 people within 20 miles of the reactor. 


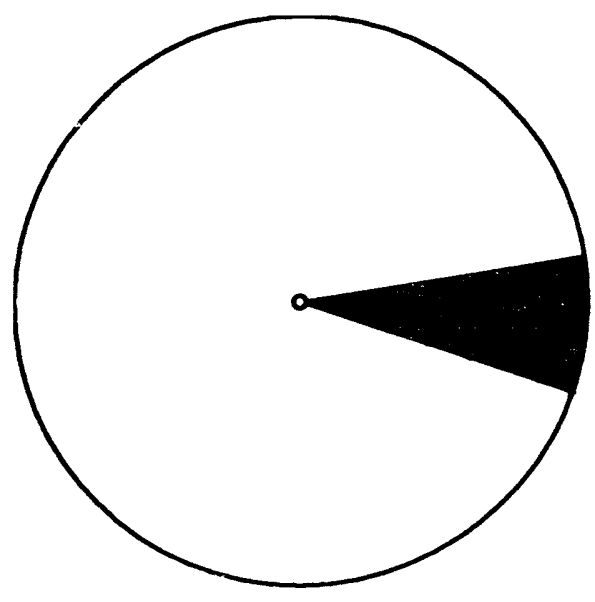

Distribution 7

$\mathrm{EF}_{\mathrm{m}}=400 \mathrm{EI}_{\mathrm{m}}=2.2 \mathrm{e} 3$

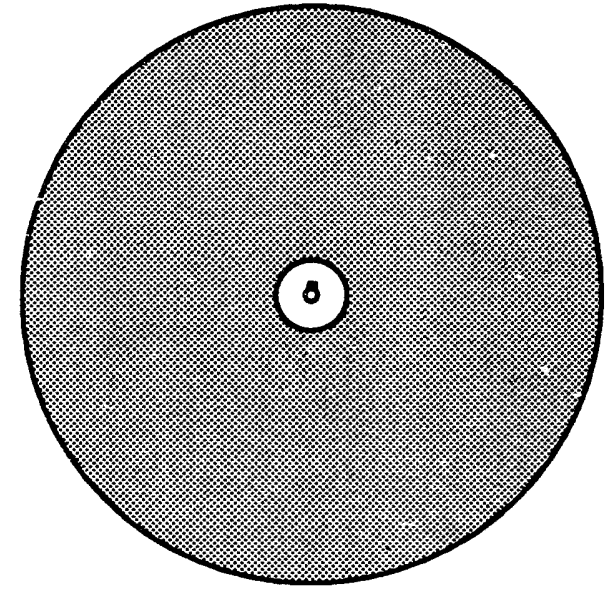

Distribution 8

City of 63001 mile out

$\mathrm{EF}_{\mathrm{m}}=560 \quad \mathrm{EI}_{\mathrm{m}}=2.3 \mathrm{e} 3$

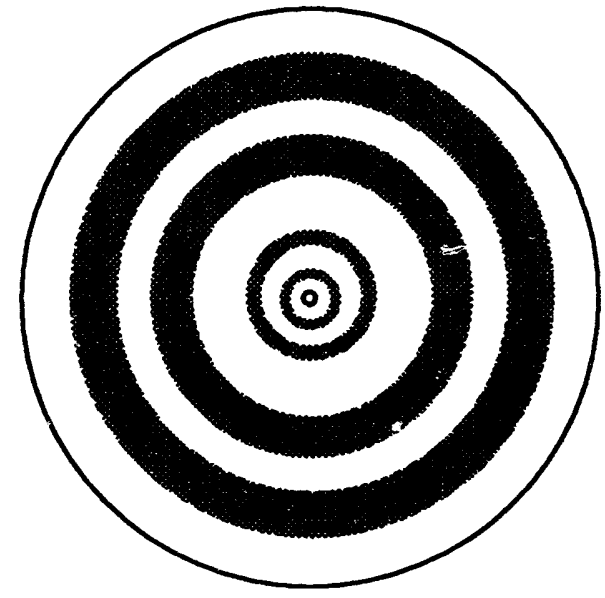

Distribution 9

$\mathrm{EF}_{\mathrm{m}}=1000 \mathrm{EI}_{\mathrm{m}}=3.9 \mathrm{e}$

Figure 1 (con't). Aldrich study population distributions. Mean early fatalities (EF m) and mean early injuries ( $\mathrm{EI}_{\mathrm{m}}$ ) for population distributions assuming SSI release, a 1120 MWe reactor, summary evacuation, New York City Meteorology, and a uniform wind rose. All nine distributions contain 989,000 people within 20 miles of the reactor. 
risk values because of the worst-case weather conditions. That is, a population concentrated witinin a small area will be less likely to be in the path of prevalling winds than a population evenly distributed around a plant. However, if the concentrated population area is in the path of prevailing winds, the worst-case consequences will be significantly larger than those calculated for the evenly distributed population.

The results of this study suggest that the distribution of a population around a nuclear power plant, as well as the average population density, could significantly effect the human health consequences of a nuclear accident. The results indicate that when the population is concentrated toward the outer radius of a sector, fewer estimated fatalities result than when the population is more evenly distributed within a radius.

The results of this study also indicated that exclusion zone size and evacuation rates and scenarios have the potential of significantly affecting the human health consequences of an accident. Findings indicated that large exclusion zones without an emergency response are not nearly as effective as a substantially smaller exclusion zone and a timely emergency response. For releases substantially smaller than SST1, because early health effects are usually confined to only a few miles, exclusion zones can have a substantial impact even without an emergency response.

In December 1992, Halliburton NUS completed a study of the NRC proposed population density limits and their relationship to the NRC Safety Goals [Halliburton NUS, 1992]. This study utilized the MELCOR AccidentConsequence Code System (MACCS) to calculate the levels of average individual risks which could be expected under the proposed population density limits. The values of average individual risk calculated were compared to the QHOs. Individual and population dose information was also calculated. Surry nuclear plant radiological and meteorological input data from NUREG1150 were utilized in this study.

The NUS study evaluated the human health consequences of a nuclear accident on a uniform population distribution of 500 people per square mile with an exclusion zone of 0.33 mile and a stratified population distribution in which most of the population is located between 20 and 30 miles from the reactor. The results of the NUS study indicated that the maximum values for the average individual risk of prompt and latent fatality were respectively $\mathbf{8 . 4}$ percent and 1.0 percent of the QHOs for the uniform population distribution. Comparison of the total population dose received by the uniform and stratified population distributions indicated that the the total population dose was significantly less for the stratified distribution. 


\section{Evaluation Approach}

The MELCOR Accident-Consequence Code System (MACCS) version 1.5.11.1 [Chanin et al., 1992] was utilized for the analysis of four hypothetical population distributions. The distributions were designed to be consistent with the NRC proposed population density guidelines; i.e., the distributions averaged 500 people per square mile or less over any radial distance out to 30 miles. All distributions contained a population of approximately $1,413,000$ within the 30-mile radius of the plant. A $0.4-$ mile radius exclusion zone was modeled for each distribution. The data input for the analysis of each model varied only in the distribution of the population within the 30-mile plant radius and the assumed evacuation rate.

Figure 2 illustrates the population distributions modeled for this study. The population distributions modeled were:

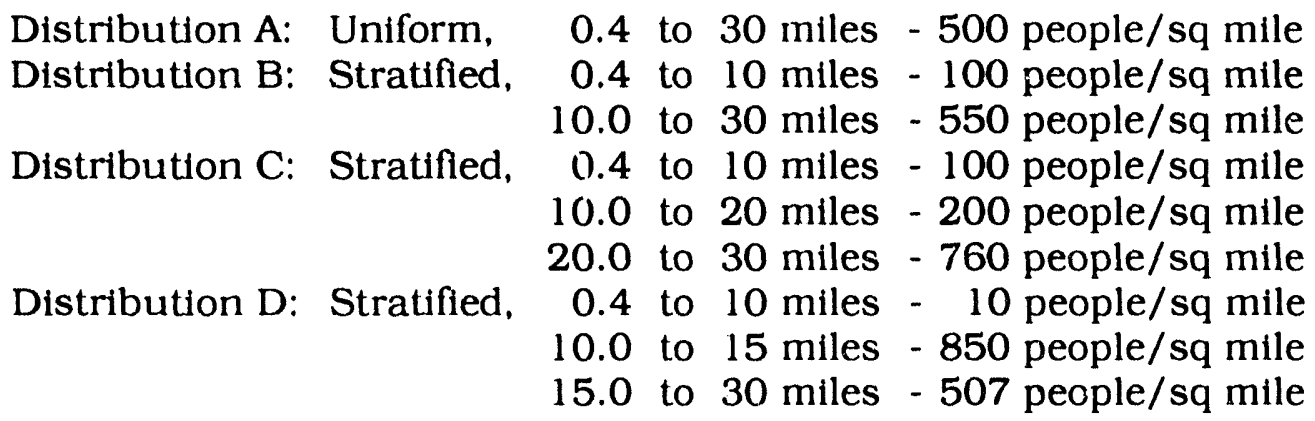

Constant population densities were assumed for each interval around the reactor to ensure the calculation of mean data independent of wind direction. A population distribution concentrated within a small area would likely result in a low mean probability of individual risk if that population center was not in the path of prevalling winds for the region. If, however, there was a low probability that the plume would be carried directly over the population center, the 95th quantile risk estimate would likely show individual risk estimates orders of magnitude higher than the mean estimates.

Human health consequences were calculated for both a $1.1-\mathrm{m} / \mathrm{s}$ and a $4.8-\mathrm{m} / \mathrm{s}$ evacuation rate. The $1.1-\mathrm{m} / \mathrm{s}$ evacuation rate was the slowest rate calculated for the NUREG 1150 study, and it represented the probable evacuation rate for the area surrounding the Zion Nuclear Reactor. The $4.8-\mathrm{m} / \mathrm{s}$ evacuation rate was the fastest rate calculated for the NUREG 1150 study, and it represented the probable evacuation rate for the area surrounding the Peach Bottom Nuclear Reactor [NUREG-1150, 1990]. Ninety-five percent of the population within 10 miles of the reactor was assumed to evacuate. No sheltering was assumed. 


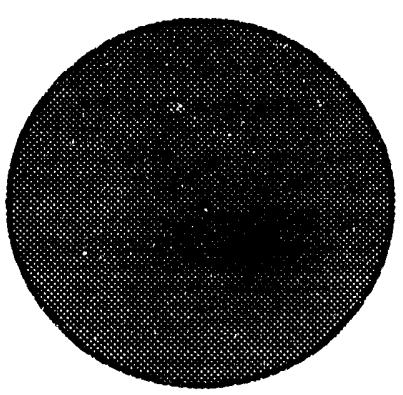

Distribution A

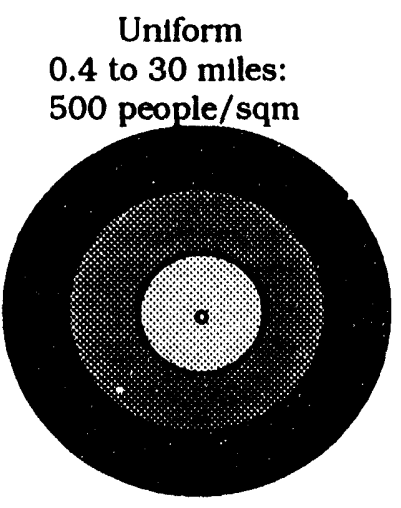

Distribution C

Stratifled

0.4 to 10 miles: 100 people/sqm 10 to 20 miles: 200 people/sqm 20 to 30 miles: 760 people/sqm

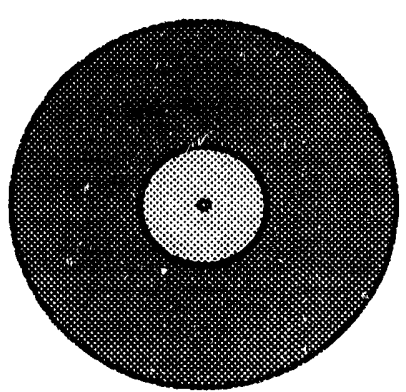

\section{Distribution B}

Stratıfied

0.4 to 10 miles: 100 people/sqm

10 to 30 miles: 550 people/sqm

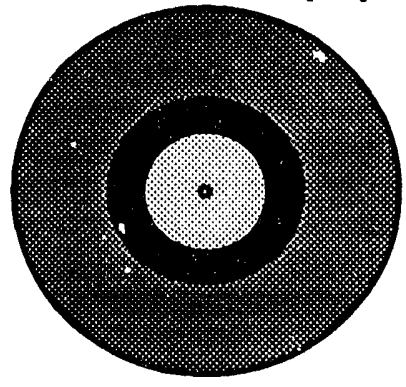

\section{Distribution D}

Stratıfled

0.4 to 10 miles: 10 people/sqm

10 to 15 miles: 850 people/sqm

15 to 30 miles: 507 people/sqm

\section{Figure 2. Population Density Distributions Modeled with MACCs.}

Calculations were performed using source terms from both a current generation LWR and an ALWR design. Both source terms were severe accident source terms calculated to have a frequency of approximately $1 \times 10^{-8}$. These severe accident source terms are highly improbable events and were not chosen to represent likely nuclear accident scenarios but rather to generate accident scenarios which would clearly illustrate the effects of different population distributions on potential accident consequences.

The LWR source term utilized for this study was a Surry (2441-MWT PWR) severe accident source term for early fatalities developed for NUREG 1150 [NUREG-1150, 1990]. The frequency calculated for this source term in the NUREG 1150 study was $4.5 \times 10^{-8}$. The ALWR source term used in this study was the CI release category discussed in the Westinghouse AP-600 Probabilistic Risk Assessment (Westinghouse, 1992). The CI release category resulted in the highest fission product release fractions and site boundary dose levels calculated for the various release categories analyzed in the AP-600 probabilistic risk assessment. This scenario models an accident in which containment fails to isolate. The frequency assigned to this release is 
$2.0 \times 10^{-8}$. The Westinghouse AP-600 is a 1940-MWT ALWR. The frequencies for the LWR and ALWR source terms were used in calculating the average individual risk of early and latent cancer fatalities.

The following sequence of events was assumed for the LWR emergency response and plume release scenario:

$\begin{array}{cl}\frac{\text { Time }}{0} & \begin{array}{l}\text { Event } \\ \text { SCRAM }\end{array} \\ 22 \mathrm{~min} & \begin{array}{l}\text { Offsite emergency response personnel notified } \\ \text { to begin emergency response procedures. }\end{array} \\ 52 \mathrm{~min} & \begin{array}{l}\text { Evacuation begins } \\ 61 \mathrm{~min}\end{array} \\ 2.8 \mathrm{hrs} & 6.1 \text { - } \mathrm{min} \text { plume is released } \\ \end{array}$

The sequence of events assumed for the ALWR scenario is as follows:

Time $\quad$ Event

$2.1 \mathrm{hrs} \quad$ Offsite emergency response personnel notified

$2.6 \mathrm{hrs} \quad$ Evacuation begins

$2.8 \mathrm{hrs} \quad 2.4-\mathrm{hr}$ plume is released

$5.2 \mathrm{hrs} \quad 5.5$-hr hour plume release

10.7 hrs 17.6-hr hour plume release

Both the LWR and ALWR scenarios assume only a 10-minute delay between the time evacuation begins and the initiation of the first plume release.

The weather category bin sampling method* was used in this problem to estimate the distribution of consequences which could result from an accident if the time of the accident's occurrence is unknown. The meteorological record utilized in this study was from the Surry nuclear plant.

The calculated human health consequences are discussed in terms of mean and 95th quantile results. The human health consequence estimates calculated relative to the radius from the reactor were:

- Average individual risk of early fatality and laient cancer fatality.

- Normalized early fatality and latent cancer ratios.

- Total population dose.

\footnotetext{
- The weather bin sampling method utilizes a year of actual recorded weather from a site. The method utilizes hourly weather recordings to account for weather variations during the progression of an accident. By using an appropriate sample of weather sequences from the year's data, a frequency distribution of estimated consequences is produced.
} 
To compare these consequence estimates for various population density assumptions, normalized early fatality and latent cancer ratios are defined as the number of early (or latent cancer) fatalities for a specified population distribution model and distance interval from the plant divided by the maximum number of early (or latent cancer) fatalities calculated for Distribution A for the scenario (source term and evacuation rate) in question.

The cancer risk factors utilized in MACCS versions prior to the 1.5.11.1 release were based on the recommendations of BEIR III [1980]. The BEIR III report, published in 1980, presented the findings of the National Research Council Committee on the Biological Effects of Ionizing Radiations. Cancer risk coefficients implemented in the MACCS version 1.5.11.1 are two to three times greater than those utilized in earlier versions of the MACCS code. These coefficients were increased in MACCS version 1.5.11.1 based on the recommendations of a 1991 report prepared by the Inhalation and Toxicology Research Institute (ITRI) [Abrahamson et al., 1991]. The recommendations in the ITRI report were based on infor reassessment of cancer health effec 'ion from an NRC sponsored Battelle Pacific Northwest Laboratorits. odels performed by Dr. Ethel Gilbert of 


\section{Evaluation Results}

The data presented in this section are based on accident scenarios estimated to have probabilities of occurrence of not more than one in $4.5 \times 10^{8}$ (LWR) or $2.0 \times 10^{8}$ (ALWR) reactor years of operation. These probabilities are included in the calculation of average individual risks. These probabilities are not included in the data which represent early fatality, latent cancer, and total population dose information. Early fatality, latent cancer, and total population dose are conditional consequences based on the occurrence of the accident scenario modeled in this study. The early and cancer fatality data represented in this section have been normalized with respect to the uniform distribution, Distribution A. The normalized early fatality ratio is defined as the number of early fatalities calculated for a specific interval and population distribution divided by the maximum early fatalities calculated for Distribution $A$ for the represented data series. The normalized cancer fatality ratio is defined as the number of cancer fatalities calculated for a specific interval and population distribution divided by the maximum cancer fatalities calculated for Distribution A for the represented data series.

The average individual risk for early fatalities and latent cancers calculated for the LWR scenario is presented in Figures 3 and 4. The average risk numbers, being independent of population density per square mile, were identical for each population distribution. The average individual risk of early fatality is zero beyond 10 miles from the reactor and, for the $1.1 \mathrm{-m} / \mathrm{s}$ evacuation rate, decreased by two orders of magnitude from 0.4 to 3.5 miles from the reactor. Figure 4 indicates that the maximum average individual risk from latent cancers, for the $1.1-\mathrm{m} / \mathrm{s}$ evacuation rate, was between 1.3 and 2.0 miles from the reactor. The latent cancer risk, for the $1.1-\mathrm{m} / \mathrm{s}$ evacuation rate decreased by approximately an order of magnitude from 0.4 to 10.0 miles from the reactor. Figures 3 and 4 also illustrate the significant reduction in average individual risk achieved with the $4.8-\mathrm{m} / \mathrm{s}$ evacuation rate. Figure 4 indicates that the average individual risk of latent cancer for the $4.8-\mathrm{m} / \mathrm{s}$ evacuation rate increased at the 10-mile radius from the reactor. The average individual cancer risk increased at the 10-mile radius because only the population out to 10 miles is assumed to evacuate. Average individual risk beyond 10 miles is therefore independent of evacuation rate.

Figure 5 presents a plot of the normalized early fatality ratio calculated for each distribution for the LWR $1.1-\mathrm{m} / \mathrm{s}$ evacuation rate scenrio. The 1.0 to $3.0-\mathrm{mile}$ interval from the reactor has nearly ten times the area of the 0.4- to 1.0-mile interval and therefore a significantly higher population than the $0.4-$ to $1.0-$ mile interval for each distribution. The second interval subsequently has a higher number of early fatalities for each distribution than the first interval. The uniform distribution has nearly 5 times the number of early fatalities of any of the remaining distributions in this interval. Figure 6 plots the normalized early fatality ratio per interval for Distribution A, LWR, for both the $1.1-\mathrm{m} / \mathrm{s}$ and the $4.8-\mathrm{m} / \mathrm{s}$ evacuation rates. The increase of the evacuation rate to $4.8-\mathrm{m} / \mathrm{s}$ significantly reduces the number of early fatalities within 3 miles of the reactor. 


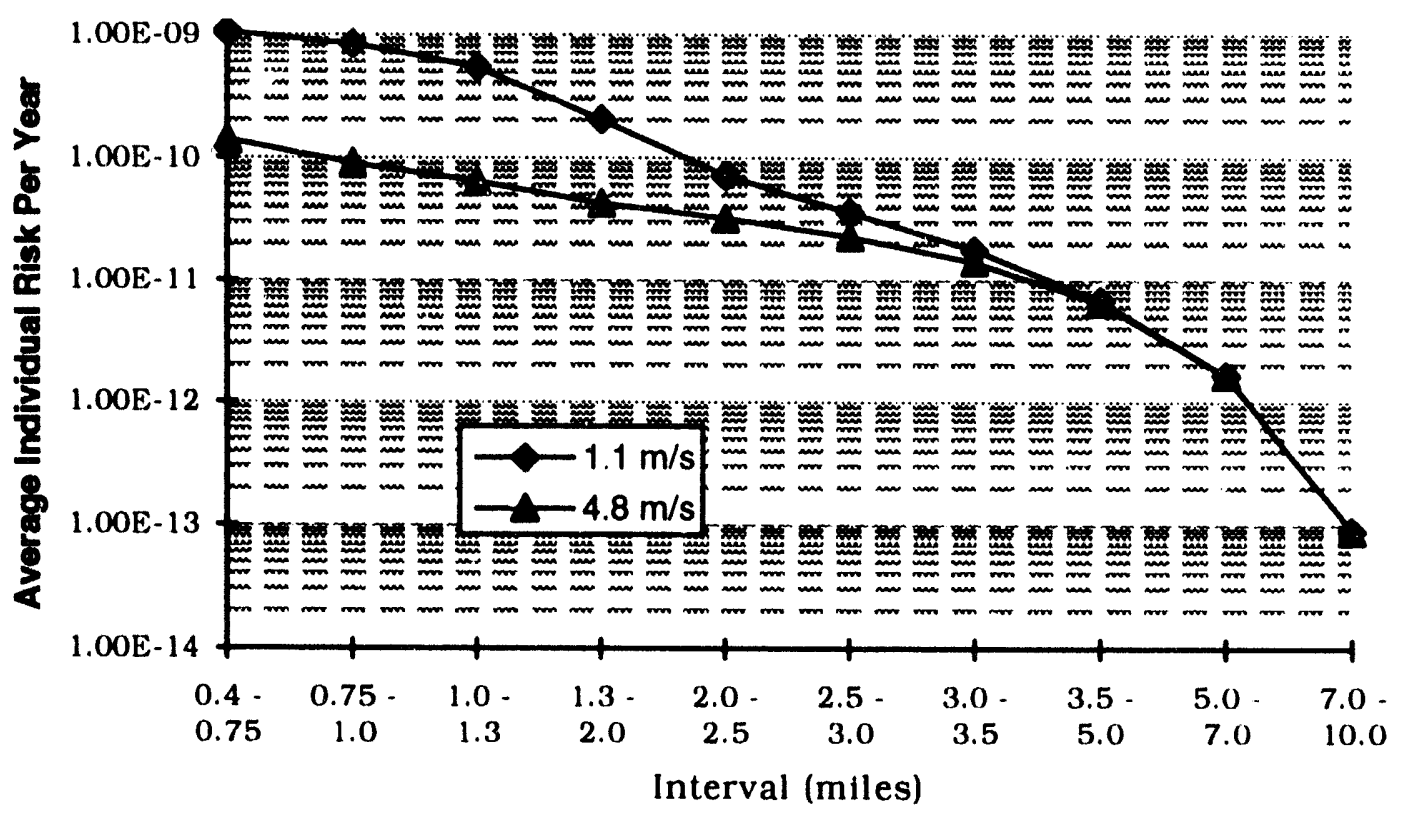

Figure 3. LWR Scenario Average Individual Risk of Early Fatalities.

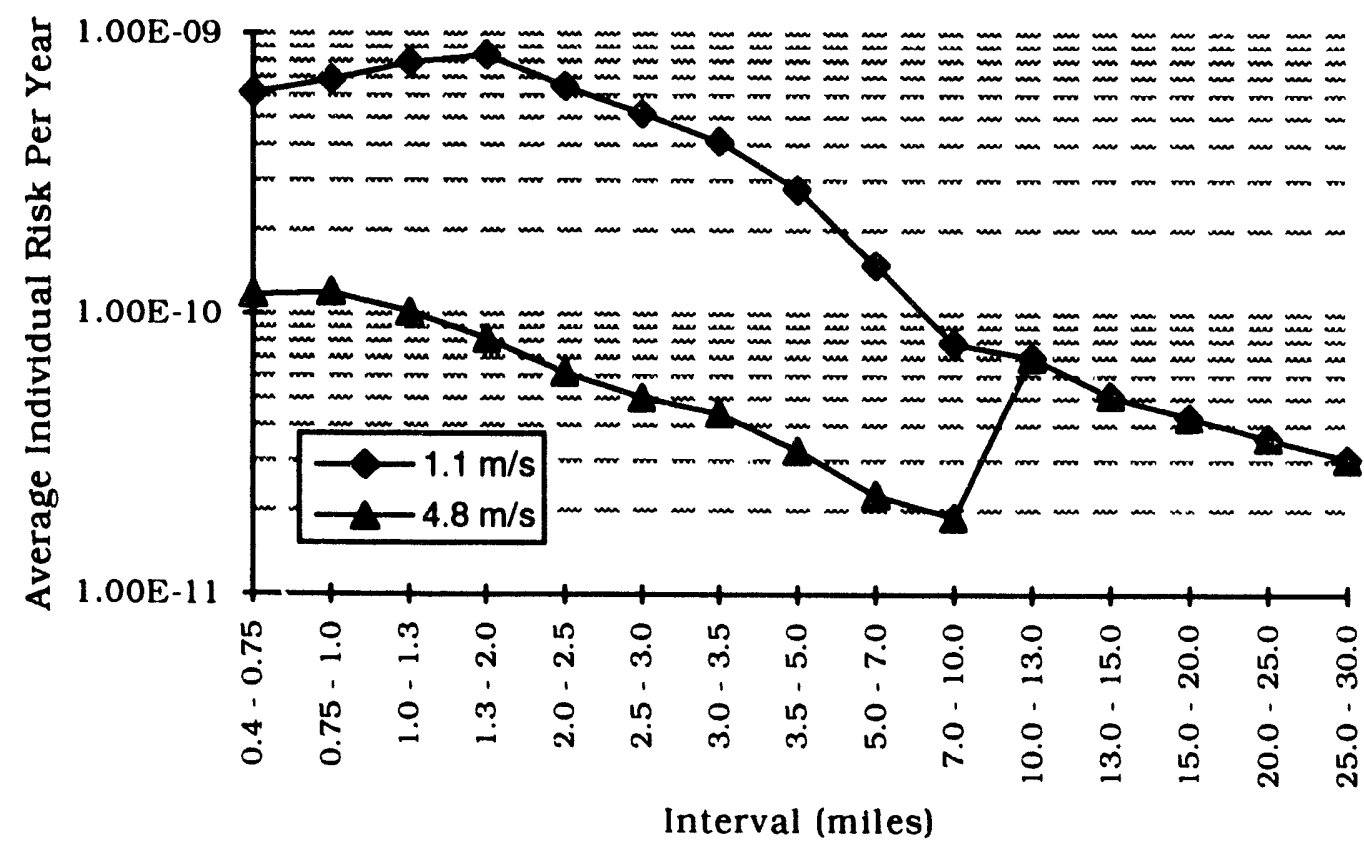

Figure 4. LWR Scenario Average Individual Latent Cancer Risk. 


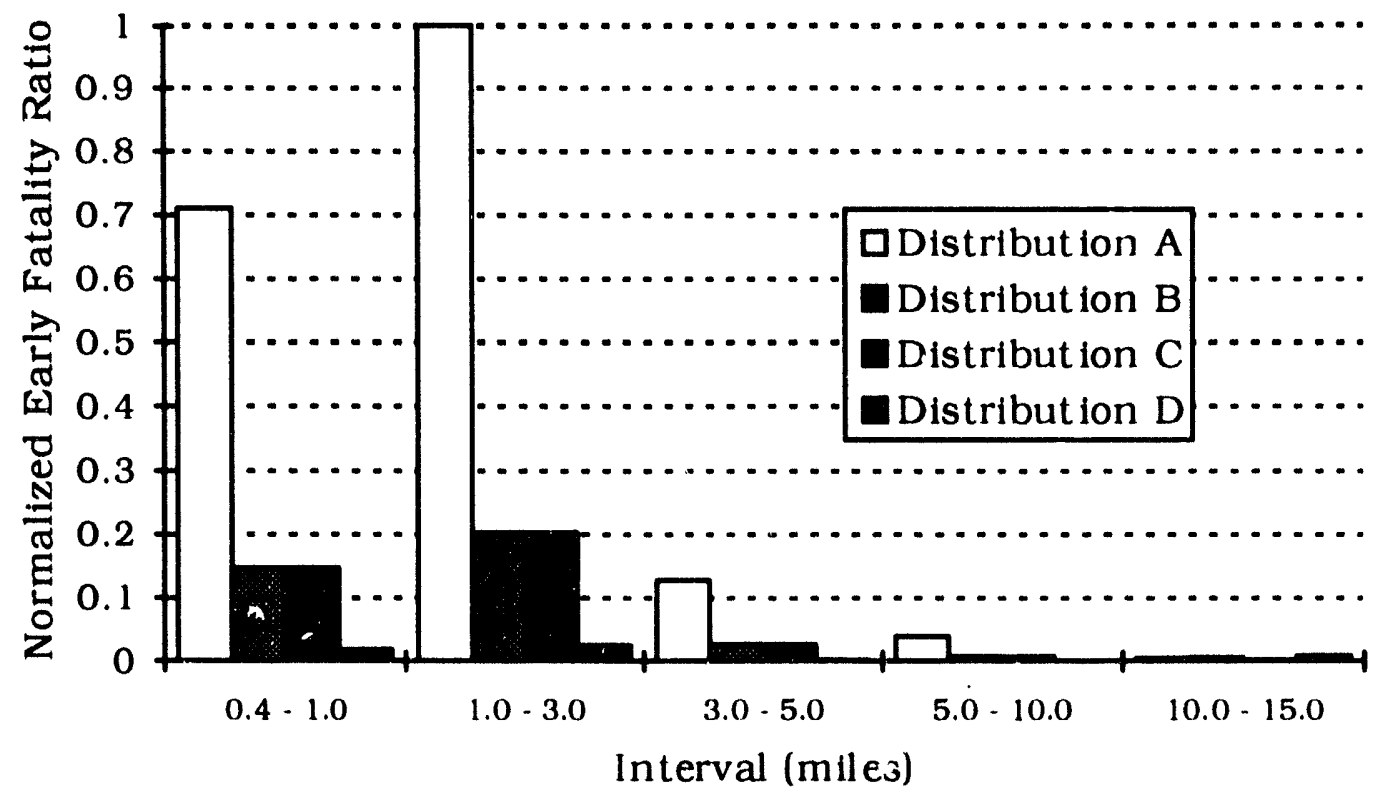

Figure 5. LWR Scenario Normalized Early Fatality Ratio per Interval for the 1.1-m/s Evacucation Rate. Normalized Eariy Fatality Ratio = [Calculated carly fatalities]/[Maximum early fatalities calculated for Distribution Al.

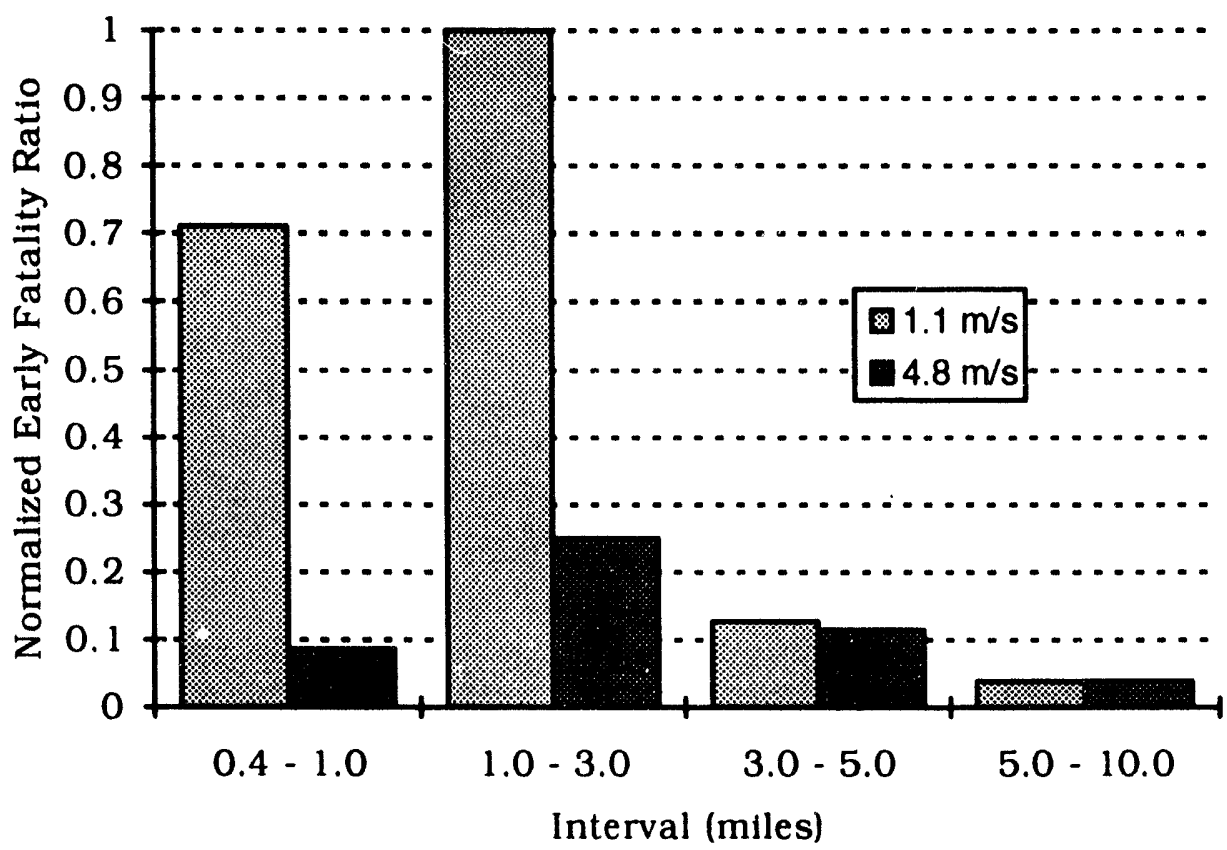

Figure 6. LWR Scenario Distribution A Normalized Early Fatality Ratios for $1.1-\mathrm{m} / \mathrm{s}$ and $4.8-\mathrm{m} / \mathrm{s}$ Evacuation Rates. Normalized Early Fatality Ratio = [Calculated early fatalities]/[Maximum early fatalities calculated for Distribution A, 1.1-m/s evacuation rate]. 
The LWR normalized cancer fatality ratios for each distilbution out to 30 miles are plotted in Figure 7. Figure 8 presents a plot of the LWR normalized cancer fatality ratios for each distribution out to 30 miles. Figure 7 illustrates that the uniform distribution. Distribution A, had the highest number of total cancer fatalities. Figure 8 indicates that Distribution A's high population density per square mile within 10 miles of the reactor resulted in Distribution A's high cancer fatality numbers. Distribution $\mathrm{C}$ had the lowest number of total cancer fatalities, the lowest population density between 10 and 20 miles, and the highest population density between 20 and 30 miles. Although the risk of latent cancer decreases significantly at distances greater than 10 miles from the reactor, Figure 8 indicates that the total estimated number of latent cancers increases. This increase in predicted latent cancers is the result of the increase in the size of the total affected population as the radius from the reactor increases.

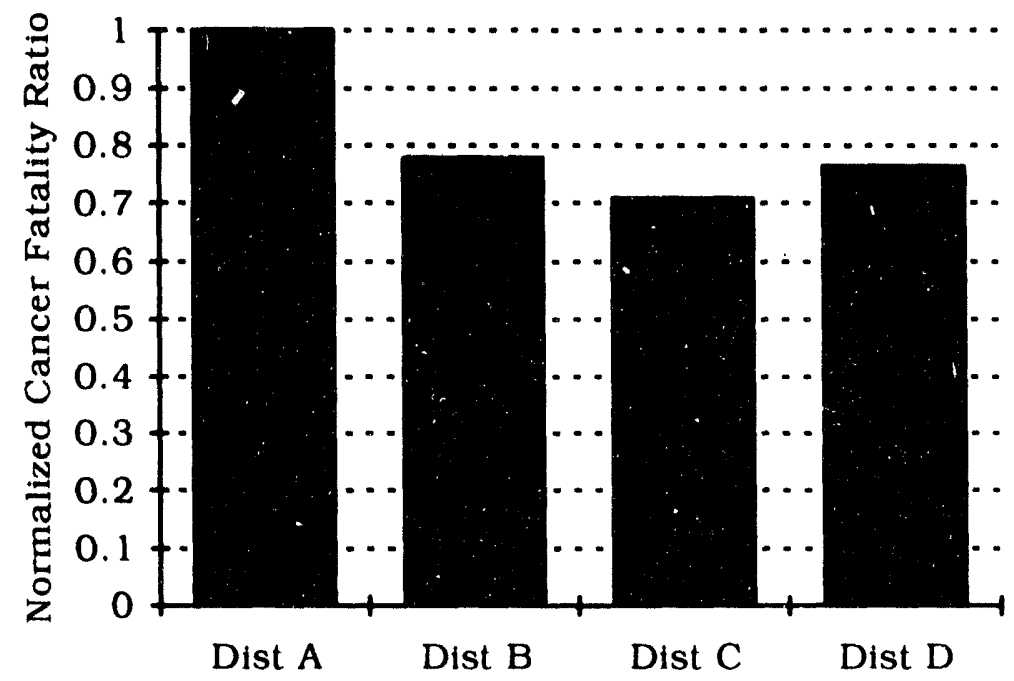

Figure 7. LWR Scenario Normalized Cancer Fatality Ratios Within the 30-Mile Radius of the Reactor for the $1.1-\mathrm{m} / \mathrm{s}$ Evacuation Rate. Normalized Cancer Fatality Ratio $=$ [Calculated cancer fatalities]/[Distribution $A$, 1.1-m/s evacuation rate, calculated cancer fatalities].

LWR population dose information is presented in Figure 9. This plot indicates that for a $1.1-\mathrm{m} / \mathrm{s}$ evacuation time, Distribution A received the highest total population dose and Distribution $C$ received the lowest. Distribution $D$, with the highest population density beyond 10 miles, received the second lowest total population dose. This plot also indicates that the population dose received by Distribution $A$ for the $1.1-\mathrm{m} / \mathrm{s}$ evacuation time was significantly reduced in the $4.8-\mathrm{m} / \mathrm{s}$ evacuation scenario. These data indicate that evacuation is most important when relatively high average population densities exist close to the facility. 


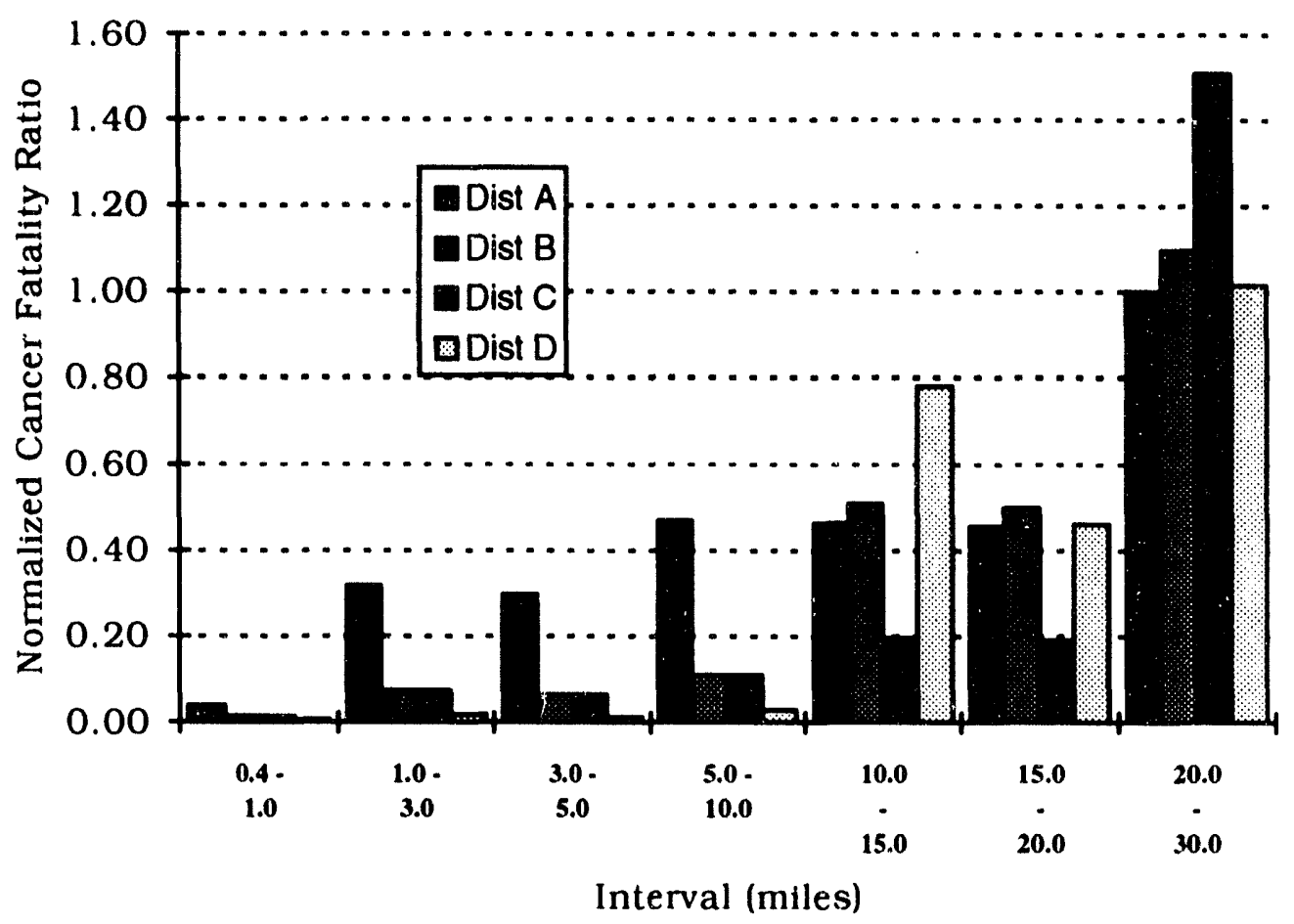

Figure 8. LWR Scenario Normalized Cancer Fatality Ratios per Interval. $1.1-\mathrm{m} / \mathrm{s}$ evacuation rate. Normalized Cancer Fatality Ratio $=$ [Calculated cancer fatalities]/[Distribution A maximum calculated cancer fatalities].

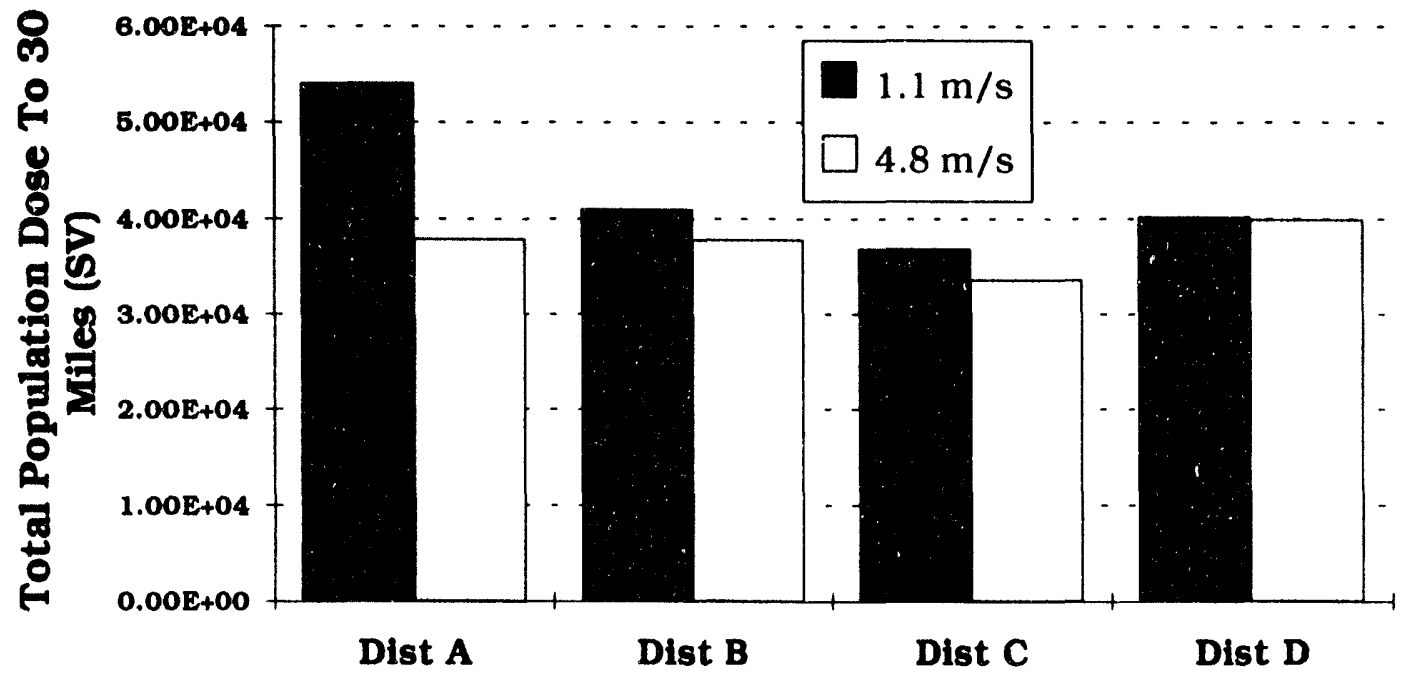

Figure 9. LWR Scenario Total Population Dose Within the 30-Mile Radius of the Reactor. 
Figures 10 and 11 plot both the mean and 95th quantile LWR results for average individual risk for early futalities and latent cancers, respectively. The 95th quantile average individual risk results for both early fatalities and latent cancers are within an order of magnitude of the mean results. The average individual risk estimates do not significantly increase for 95th quantile weather conditions because the populations are azimuthally uniform.

Figures 12 and 13 plot the LWR normalized early and cancer fatality ratios for the mean and 95th quantile for each distribution. Figures 12 and 13 show that for 95th quantile weather conditions, Distribution A has the maximum number of estimated early and latent cancer fatalities.

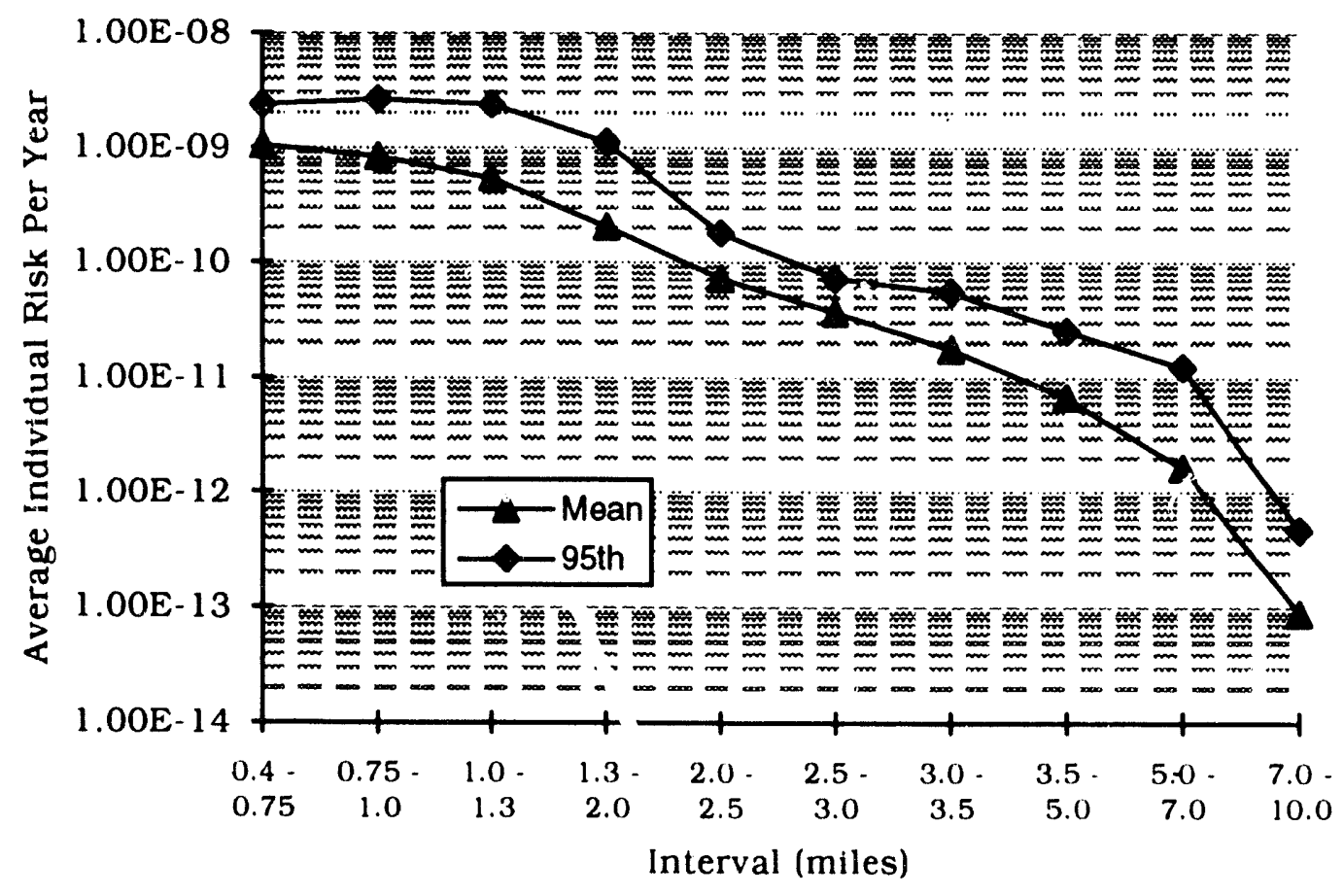

Figure 10. LWR Scenario Mean and 95th Guantile Average Individual Risk of Early Fatalities. 1.1-m/s evacuation rate. 


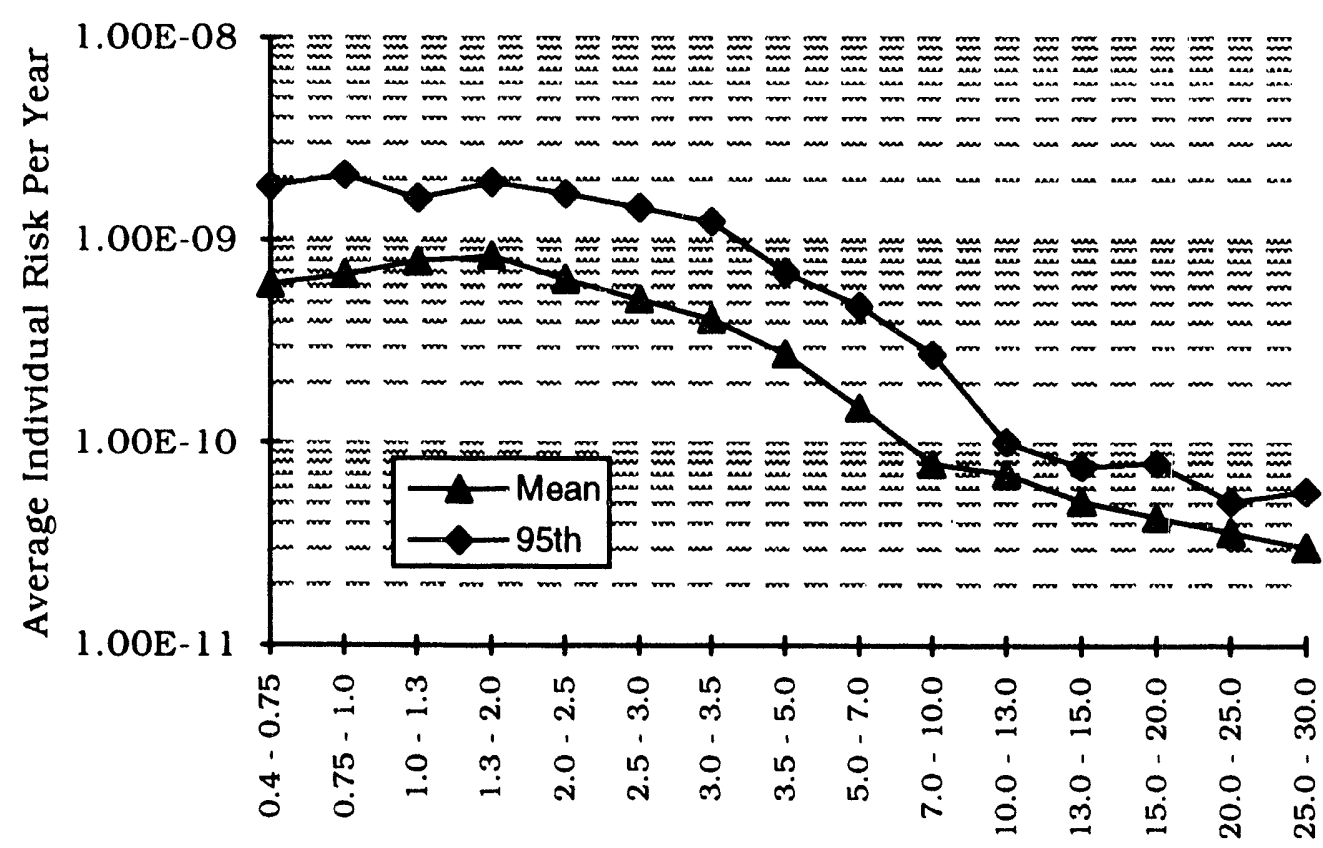

Interval (miles)

Figure 11. LWR Scenario Mean and 95th Quantile Average Individual Risk of Cancer Fatalities. 1.1-m/s evacuation rate.

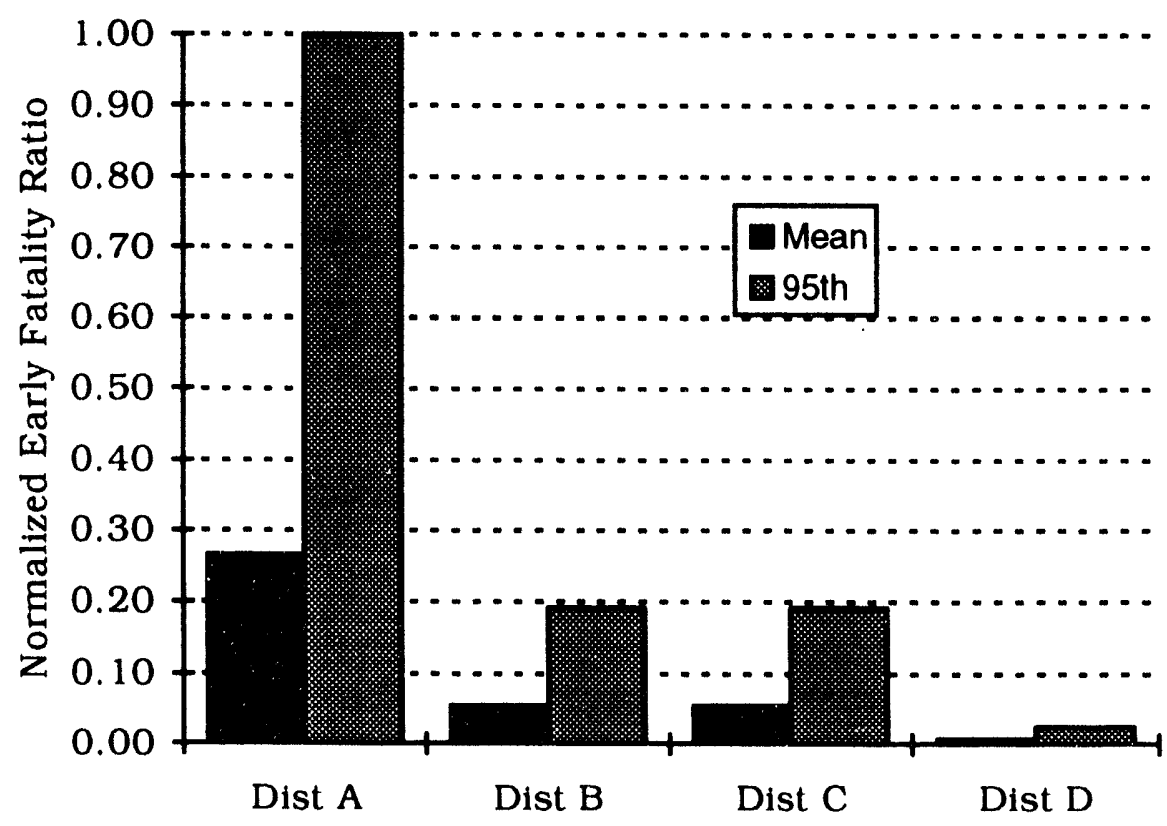

Figure 12. LWR Scenario Normalized Early Fatality Ratios for Mean and 95th Quantile Weather Conditions. 0.4- to 30-mile radius from reactor. 1.1-m/s evacuation rate. Normalized Early Fatality Ratio = [Calculated carly fatalities]/[Maximum early fatalities value calculated for Distribution A, 95th quantile]. 


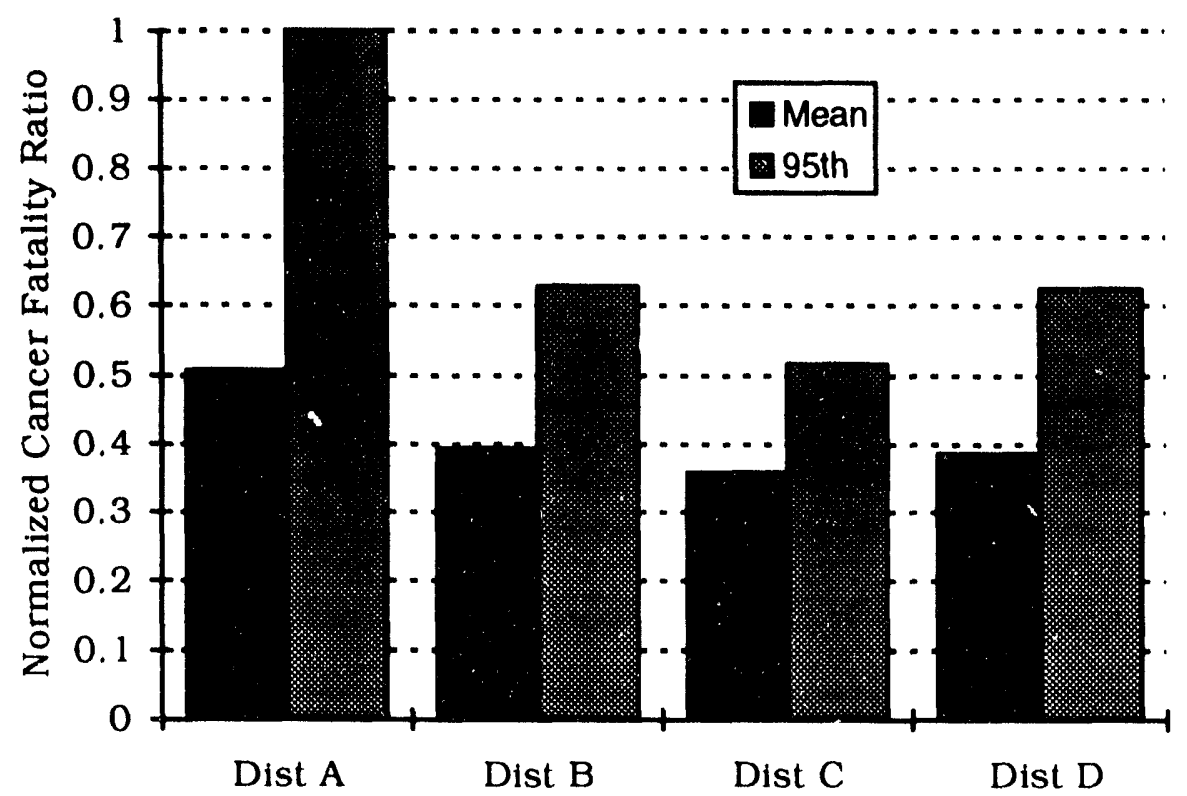

\section{Figure 13. LWR Scenario Normalized Cancer Fatality Ratios for Mean and 95th Guantile Weather Conditions. 0.4- to 30-mile radius from reactor. $1.1-\mathrm{m} / \mathrm{s}$ evacuation rate. Normalized Cancer Fatality Ratio $=$ [Calculated cancer fatalities]/[Maximum cancer fatalities value calculated for Distribution A, 95th quantile].}

Typically, the same pattern of results obtained for the LWR calculations were exhibited for the onsequences calculated for the ALWR in terms of Distributions A and C, respectively, exhibiting the highest and lowest level of consequences. The average individual risk of early fatality was nearly four orders of magnitude less for the ALWR scenario than for the LWR scenario, and there was a zero probability of early fatality beyond 1.3 miles. The average individual risk of latent cancer was greater than one order of magnitude less for the ALWR scenario than for the LWR scenario. The increase in the evacuation rate from $1.1-\mathrm{m} / \mathrm{s}$ to $4.8-\mathrm{m} / \mathrm{s}$ has less effect on the consequences in the ALWR scenario and there were greater differences between the mean and 95th quantile data in the ALWR calculations.

The ALWR average individual risk of early fatality is plotted in Figure 14 for the $1.1-\mathrm{m} / \mathrm{s}$ and $4.8-\mathrm{m} / \mathrm{s}$ evacuation rates and for a no-evacuation scenario. The ALWR average individual risk of early fatality was the same for both evacuation scenarios and an order of magnitude higher for the scenario which assumed no evaciation. The ALWR scenario average individual risk of early fatality decreases by four orders of magnitude between the 0.4 and 1.3 mile radius from the reactor for both the evacuation and no evacuation scenario. Figure 15 is a plot comparing the ALWR mean and 95th quantile average individual risk 
of early fatality data. The risk of early fatality for the 95th quantile was an order of magnitude greater than that calculated for the mean, which was a greater difference than that exhibited by the LWR scenario.

Figure 16 plots ALWR normalized early fatality ratio data for the four distributions. The distributions exhibit the same relative level of consequences as for the LWR scenario. Figure 17 plots the ALWR average individual risk of latent cancer, and Figure 18 plots the normalized total cancer fatality ratio for each distribution. Figure 18 shows that the ALWR scenario produces the same ranking for consequences in terms of popuiation distributions as the LWR scenario; however, the magnitude of the difference between the consequences of the distributions is smaller for the ALWF scenario.

Figure 19 plots the total population dose within 30 miles of the reactor for the ALWR scenario. This plot shows the same relative ranking between population distributions for the ALWR scenario as for the LWR scenario for the individual evacuation speeds. The ALWR scenario did not show as great a difference in the population dose estimates between evacuation rates as the LWR scenario.

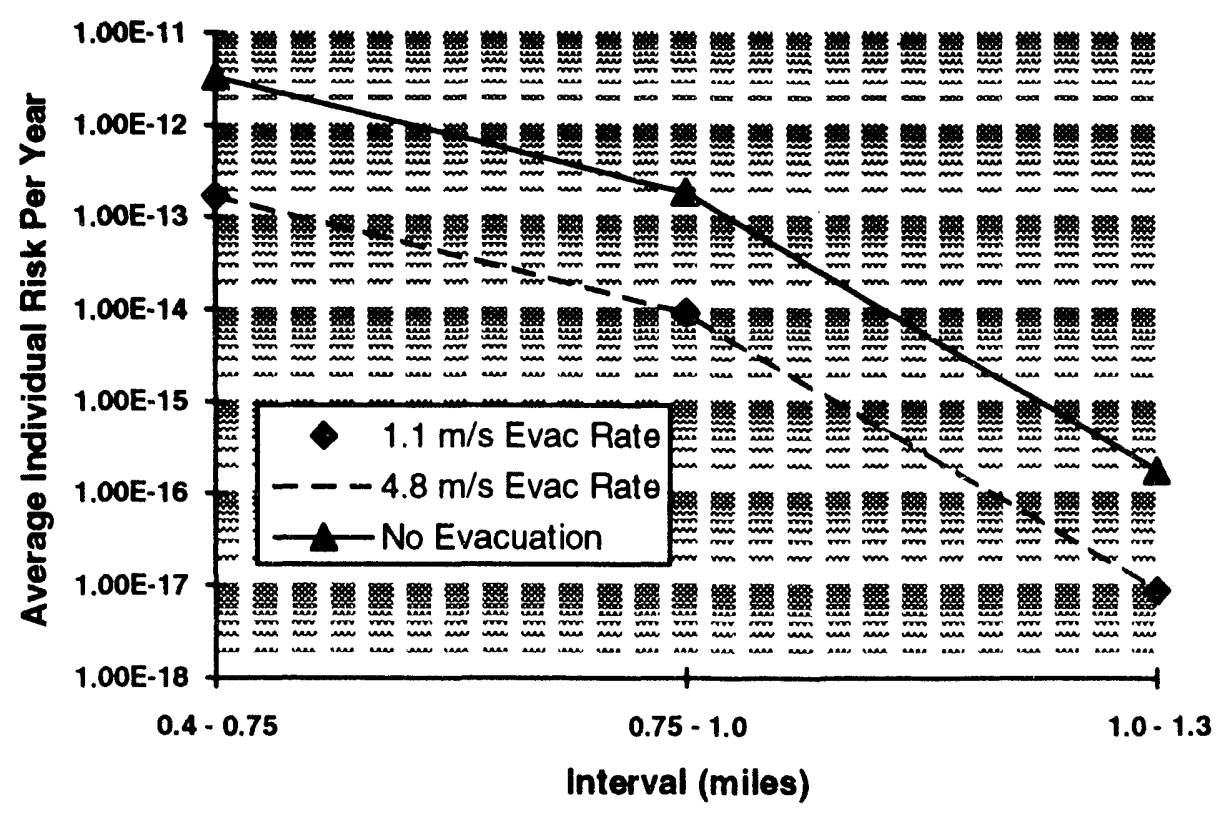

Figure 14. ALWR Scenario Average Individual Risk of Early Fatalities. 


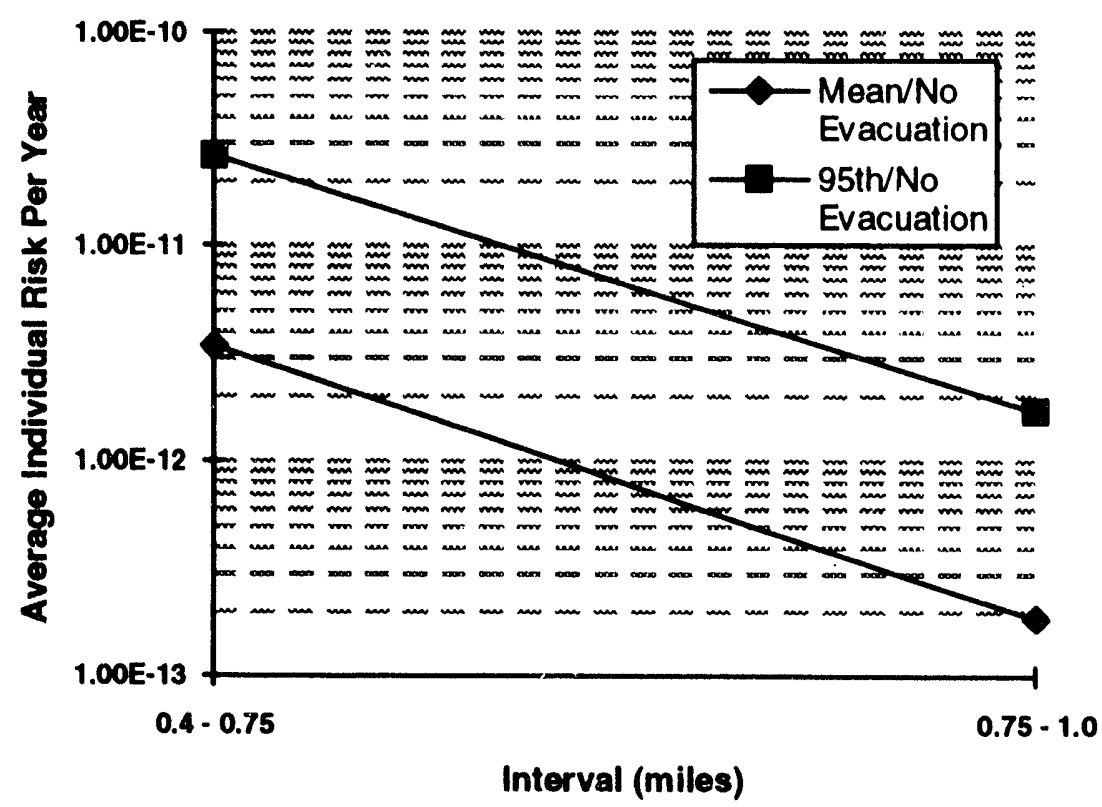

Figure 15. ALWR Scenario Mean and 95th guantile Average Individual Risk of Early Fatality.

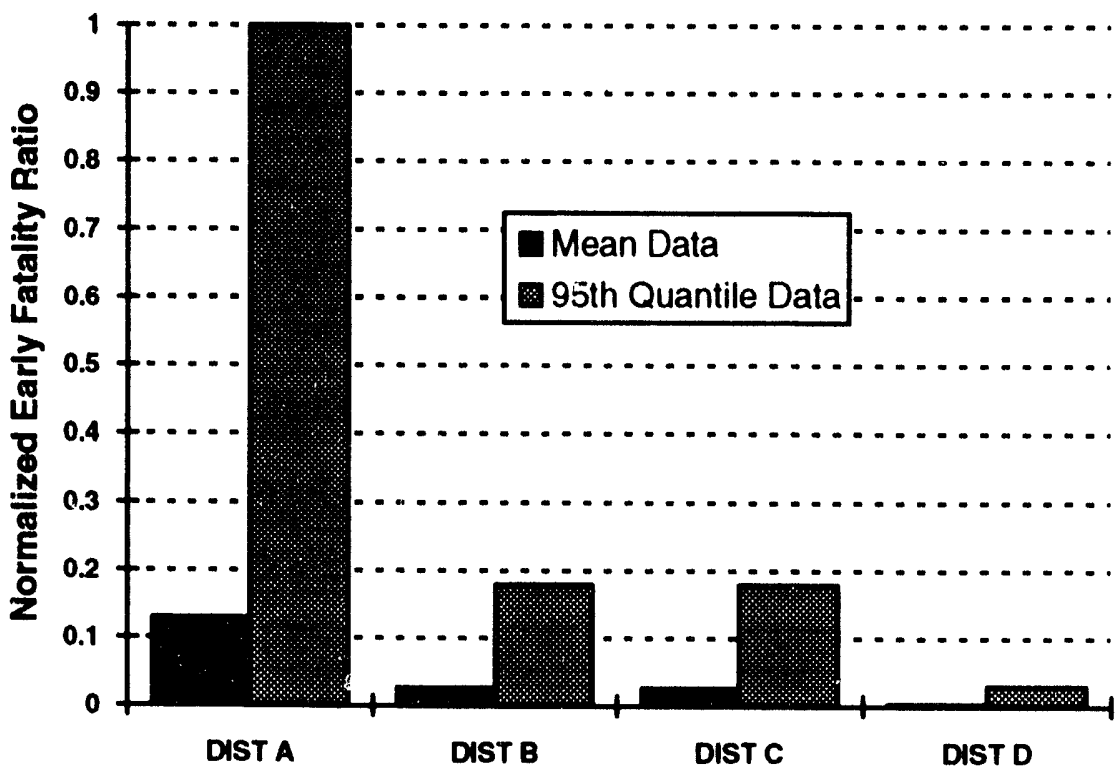

Figure 16. ALWR Scenario Normalized Early Fatality Ratios for Mean and 95th Quantile Weather Conditions. 0.4- to 30-mile radius from reactor. 1.1-m/s evacuation rate. Normalized Early Fatality Ratio = ICalculated early fatalities]/[Maximum early fatalities value calculated for Distribution A, 95th quantile]. 


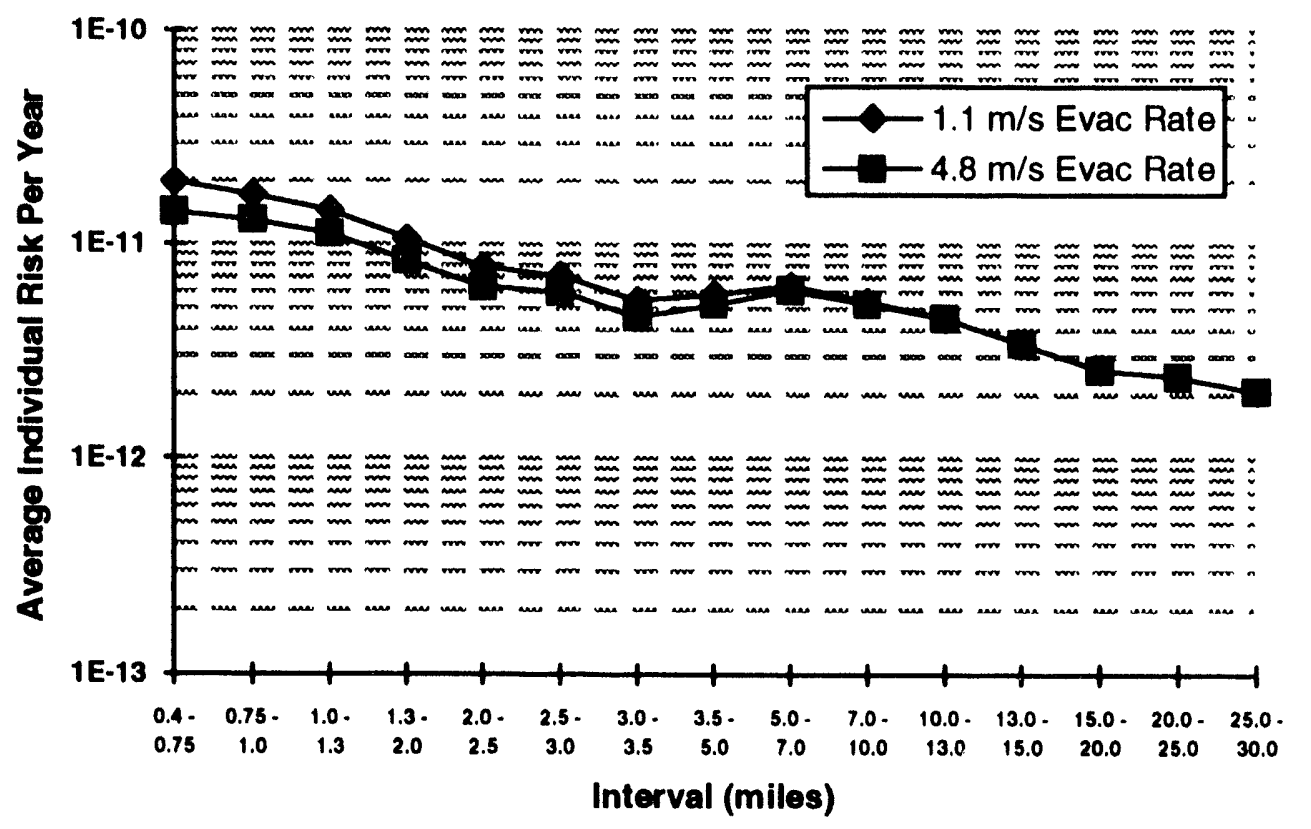

Figure 17. ALWR Scenario Average Individual Risk of Latent Cancer.

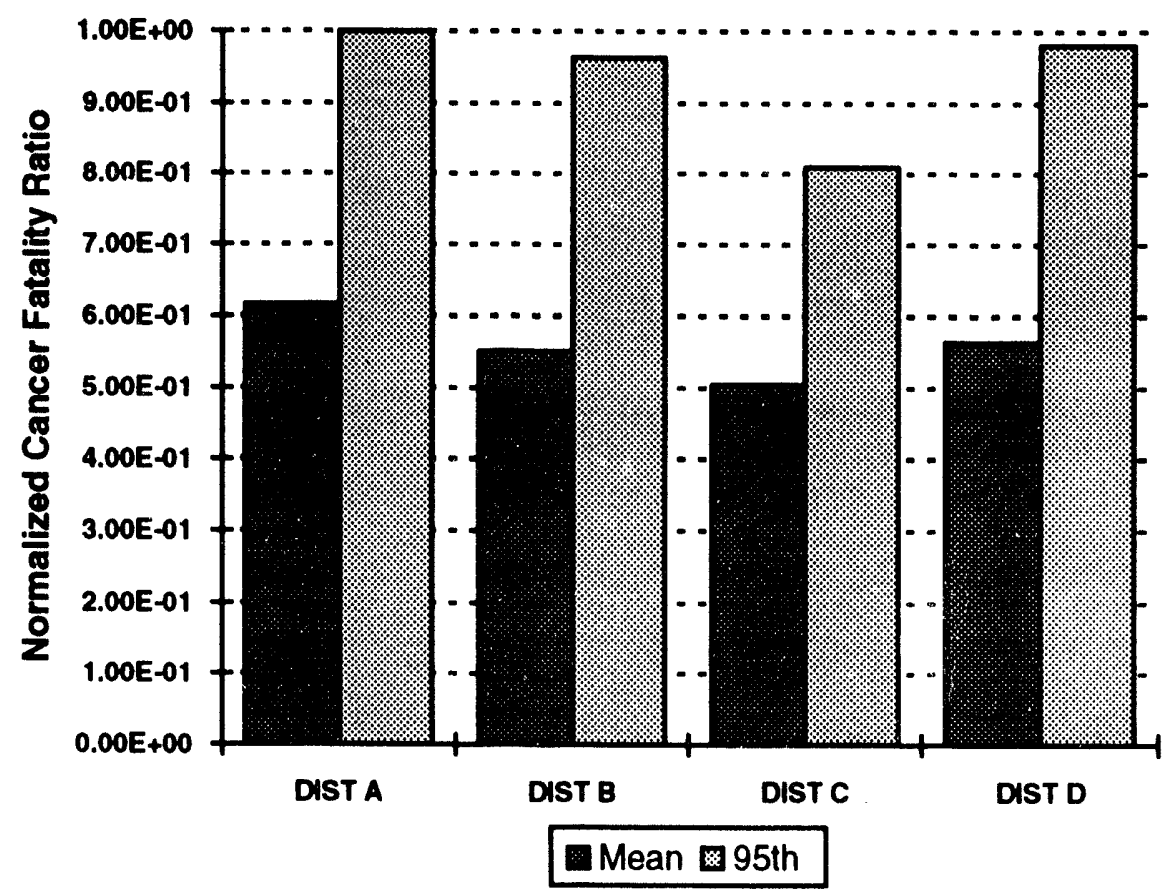

Figure 18. ALWR Scenario Normalized Total Cancer Fatality Ratio Within 30 Miles of the Reactor for the $1.1-\mathrm{m} / \mathrm{s}$ Evacuation Rate. Normalized

Early Fatality Ratio = [Calculated early fatalities]/[Maximum early fatalities value calculated for Distribution $A, 95 t h$ quantile]. 


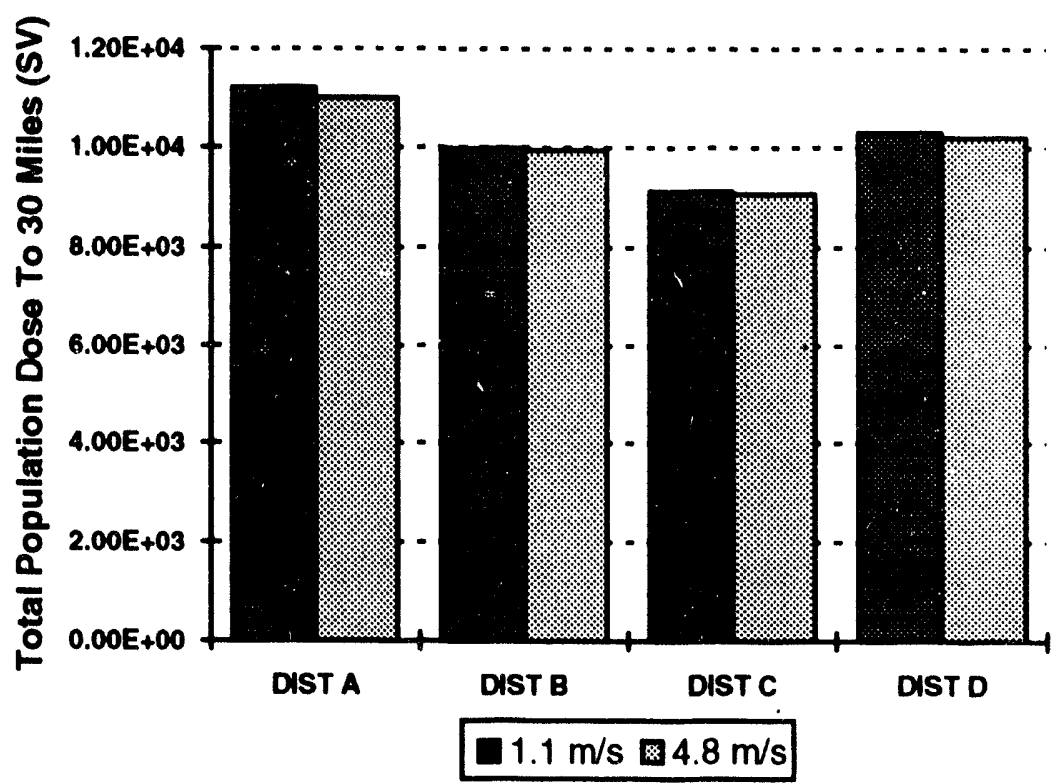

Figure 19. ALWR Scenario Total Population Dose (mean value) Within 30 Miles of the Reactor. 


\section{Conclusions}

The results of this study indicate that the levels of average individual risk of fatality typically decrease as distance from the reactor increases. Subsequently, the magnitude of the population density relative to the distance from the reactor can significantly affect the level of human health consequences resulting from a severe accident. Beyond 10 miles from the reactor for the LWR scenario and beyond 1.3 miles for the ALWR scenario, the average individual risk of early fatality is zero. The LWR scenario average individual risk of early fatality for the $1.1-\mathrm{m} / \mathrm{s}$ evacuation rate decreased by two orders of magnitude between 0.4 to 3.5 miles from the reactor. The average individual risk of early fatality for the ALWR scenario decreased by four orders of magnitude between the 0.4 - to 1.3 -mile radius from the reactor.

The LWR scenario maximum average individual risk from latent cancers, for the $1.1-\mathrm{m} / \mathrm{s}$ evacuation rate, occurred between 1.3 and 2.0 miles from the reactor. The LWR scenario latent cancer risk, ior the $1.1-\mathrm{m} / \mathrm{s}$ evacuation rate, decreased by approximately an order of magrnitude between 0.4- to 10.0 miles from the reactor. The average individual risk of latent cancer for the ALWR scenario did not decrease with distance as significantly as the LWR scenario. There was less than a one-order-of-magnitude decrease in the average individual risk of latent cancer as the distance from the reactor increased to 30 miles. The average individual risk of latent cancer for the ALWR scenario was highest in the interval nearest the reactor $(0.4-$ to 0.75 -mile radius). The maximum average individual risk of latent cancer for the ALWR scenario was an order of magnitude less than the maximum calculated for the LWR scenario.

The results of this study indicate that evacuation rates can affect the average individual risk estimates within a 5-mile radius of the reactor, but that the magnitude of this effect is dependent on the source term. The risk of early fatality and latent cancer in the LWR scenario was reduced by nearly an order of magnitude in some intervals as a result of increasing the evacuation rate from $1.1-\mathrm{m} / \mathrm{s}$ to $4.8-\mathrm{m} / \mathrm{s}$. The LWR scenario results indicate that evacuation is most important when the population density is relatively high close to the facility. The increase in the evacuation rate has little effect on the average individual risk values for the ALWR scenario. However, the ALWR scenario, which assumed no evacuation, had an average individual risk of early fatality one order of magnitude higher than the evacuation scenarios.

Aldrich et al. (1982) determined that exclusion zone size and evacuation rates and scenarios have the potential of significantly affecting the human health consequences of an accident. Findings indicated that large exclusion zones without emergency response (e.g. evacuation) are not nearly as effective as a substantially smaller exclusion zone and a timely emergency response. However, because early health effects are usually confined to only a few miles, exclusion zones can have a substantial impact even without an emergency response. 
The Aldrich study also indicated that accident-consequence calculations, out to the 99 th percentile, were only marginally impacted by site-specific meteorology. This finding indicates that site-specific weather is not a critical parameter for accident-consequence calculations. However, the variation in the 99th percentile results indicated that site-specific weather, particularly sites with a high frequency of precipitation, can significantly increase accidentconsequences under worst-case weather conditions. Site-specific worst-case weather conditions are subsequently an important parameter to consider in the determination of site suitability.

The proposed population density guidelines limit the total population surrounding a reactor. Table 1 lists the total population for various radii from the plant allowed under the proposed guidelines (500 people per square mile). The proposed population density guidelines would subsequently serve to limit the total human health consequences and the interdiction costs resulting from a severe accident. The results of this study, however, indicate that there may be alternatives to the proposed population density guidelines which would provide equivalent or better protection to human health in the event of a nuclear accident.

\begin{tabular}{cc}
\hline Table 1. Allowable Population Under NRC Proposed \\
Guidelines. \\
Radius (miles) & Total Allowable Population \\
& \\
1 & 1,319 \\
5 & 39,019 \\
10 & 156,828 \\
20 & 353,178 \\
30 & 628,067 \\
& $1,413,465$ \\
\hline
\end{tabular}

Potential health risks to the population typically decrease as distance from the reactor increases, and the highest risk to the population is within the first 10 miles of the reactor. Guidelines which would address the actual distribution of the population in the vicinity of the plant rather than the average population density could have a quantitative effect on the calculated risks. Estimated evacuation rates, dependent on the local population distribution and available evacuation routes, have been demonstrated to affect the calculated accident . human health consequences and are therefore also an important parameter to be included in plant site selection.

A review of policies abroad applicable to the establishment of maximum population density limits within any radius of a hazardous facility indicates 
that the Dutch and Hong Kong governments have institutionalized policies which define levels of acceptable and unacceptable risk as functions of the potential number of fatalities and the probability of the event. The Dutch standard begins at a maximum acceptable risk of one in $10^{5}$ per year for accidents which could result in 10 fatalities, as less than 10 are accounted for by individual risk standards (individual fatality rate of one in one million per year). As the number of potential fatalities increase, the probability must decrease significantly. A 10-fold increase in the estimated number of fatalities would require a corresponding 100 -fold decrease in the probability of the accident [Dutch National Environmental Policy Plan, 1989]. The Hong Kong government has established societal risk standards which require that the level of risk must not be greater than one in $10^{4}$ per year from an accident which has the potential of producing 10 fatalities. The Hong Kong standards do not consider probabilities for accidents which have the potential of producing over 1000 fatalities. The risk of these accidents is considered unaccepable regardless of the level of risk.

The specific measure used in the Safety Goal, i.e., individual risk, is (by definition) not a function of population density. The QHOs of the Safety Goals therefore do not provide a basis or rationale for the regulatory restrictions on population density in the vicinity of the reactors. Although population density limits cannot be developed from the limits on average individual risk specified by the U.S. NRC QHOs, the results of this study suggest that measures which address the distribution of the population density, including emergency response conditions, could result in lower average individual risks to the public than the proposed guidelines that require controlling average population density. Studies also indicate that an exclusion zone size, determined by emergency response conditions and reactor design (power level and safety features), would better serve to protect public health than a rigid standard applied to all sites. 


\section{References}

Abrahamson, S., M. Bender, B. Boecker, E. Gilbert, and B.R. Scott. Health Effects Models for Nuclear Power Plant Accident-Consequence Analysis, Modifications of Models Resulting From Recent Reports of Health Effects of Ionizing Radiation, Low LET Radiation, Part II: Scientific Bases for Health Effects Models, NUREG/CR-4214, Rev. 1. Part II, Addendum 1. LMF-132, Inhalation Toxicology Research Institute, Albuquerque, NM, August 1991.

Aldrich, D.C. et al., Technical Guidance For Siting Criteria Development, NUREG/CR-2239, Albuquerque, NM: Sandia National Laboratories, 1982.

BEIR III (1980) The Effects on Populations of Exposure to Low Levels of Ionizing Radiation, National Research Council Committee on the Biological Effects of Ionizing Radiations, Assembly of Life Sciences, National Academy Press, National Academy of Sciences, Washington. DC.

D. Chanin, J. Rollstin, J. Foster, and L. Miller, MACCS Version 1.5.11.1: A Maintenance Release of the Code, Sandia National Laboratories, Draft of July, 1992.

Dutch National Environment Policy Plan (1989), Premises for Risk Management, Second Chamber of the States General, session 1988-1989. 21137, no.5.

"Evaluation Of Population Distribution Relative To Meeting The Quantitative Health Objectives Of The NRC Safety Goal Policy For Offsite Risk Associated With Nuclear Power Plants," Halliburton NUS, December, 1992.

J.C Helton \& R.J. Breeding, "Calculation of Reactor Accident Safety Goals," Reliability Engineering and Systems Safety, 1992.

Severe Accident Risks: An Assessment for Five U.S. Nuclear Power Plants, Final Summary Report, NUREG-1 150, Vol. 1, December, 1990.

U.S. Nuclear Regulatory Commission, Safety Goals for the Operation of Nulcear Power Plants; Policy Statement. Federal Register, 51, (149) (4 August 1986) 28044-49.

U.S. Nuclear Regulatory Commission, SECY-89-102, "Implementation of the Safety Goal Policy," March 30, 1989, and Staff Requirements Memorandum to SECY-89-102, June 15, 1989.

U.S. Nuclear Regulatory Commission, Reactor Site Criteria: Proposed rule and proposed denial of petition for rulemaking from Free Environment. Federal Register, 57, (203) (20 October 1992) 47802-21. 
Westinghouse, AP-600 Probabilistic Risk Assessment, Document ID No. GWGC022Rev.0, June 26, 1992. 
Appendix A:

Comparison Population Density Information 
A-2 


\section{Appendix A: \\ Comparison Population Density Information}

Table A-1 presents examples of population densities per square mile for a sample group of U.S. cities. The information was obtained from the 1991 Statistical Abstract of the United States ${ }^{*}$ and is based on 1990 census data.

Table A-1. Population density per square mile for a sample group of U.S. cities.

Total

Population

Population

City

(X 1000)

per square mile

Chesapeake, VA

Scottsdale, AZ

Columbus, GA

Jacksonville, FL

Huntsville, AL

Philadelphia, PA
152

130

179

635

160

1,586
446

706

827

837

972

Table A-2 presents population density information within a 30-mile radius of U.S. reactor sites. The population density information is based on the 1990 U.S. census. The population density data include only people living within the borders of the United States, and it does not include transient populations such as vacationers or workers who do not live within the area. These data were obtained from software written by Humphrey and Rollstin*" for the U.S. Nuclear Regulatory Commission. These data indicate that there are 10 sites with operating nuclear reactors within the United States that have an average population density of greater than $\mathbf{5 0 0}$ people per square mile within 30 miles of the reactor site.

"U.S. Bureau of the Census, Statistical Abstract of the United States, 1991, U.S. Dept. of Commerce, 1991, 111 th ed.

* S.L. Humphreys \& J.A. Rollstin, Sector Population, Land Fraction, and Economic Estimation Program (SECPOP90). NUREG/CR-DRAFT, SAND93-4032, Albuquerque. New Mexico: Sandia National Laboratories, 1993. 
Table A-2. Population density (people per square mile) around U.S. nuclear power plant sites. This table includes reactors canceled after 1980. Reactors canceled after 1980 are shaded. Reactor sites with population densities greater than 500 people per square mile are in bold characters.

\begin{tabular}{|c|c|c|c|c|c|c|}
\hline \multirow{2}{*}{$\begin{array}{c}>500 \text { people } \\
\text { per sqm? }\end{array}$} & \multirow[b]{2}{*}{ Reactor } & \multicolumn{4}{|c|}{ people per square mile } & \multirow[b]{2}{*}{ Canceled } \\
\hline & & 0-5 Miles & 0-10 Miles & 0-20 Miles & 0-30 Miles & \\
\hline & Allens Creek & 28 & 40 & 44 & 128 & 1982 \\
\hline & Arkansas & 149 & 127 & 57 & 36 & \\
\hline$x$ & Bailly & 317 & 353 & 436 & 676 & 1981 \\
\hline \multirow[t]{21}{*}{$x$} & Beaver Valley & 195 & 388 & 356 & 525 & \\
\hline & Bellefonte & 46 & 70 & 52 & 49 & deferred \\
\hline & Big Rock Point & 65 & 31 & 34 & 22 & \\
\hline & Black Fox & 50 & 40 & 228 & 241 & 1982 \\
\hline & Braidwood & 156 & 87 & 105 & 148 & \\
\hline & Browns Ferry & 26 & 90 & 118 & 119 & \\
\hline & Brunswick & 74 & 57 & 79 & 60 & \\
\hline & Byron & 94 & 69 & 191 & 166 & \\
\hline & Callaway & 10 & 16 & 31 & 50 & \\
\hline & Calvert Cliffs & 100 & 86 & 91 & 87 & \\
\hline & Catawba & 212 & 328 & 484 & 346 & \\
\hline & 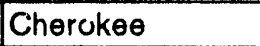 & 51 & 115 & 137 & 212 & 1982 \\
\hline & Clinton & 12 & 38 & 42 & 115 & \\
\hline & Comanche Peak & 47 & 62 & 33 & 47 & \\
\hline & Cooper & 10 & 17 & 16 & 18 & \\
\hline & Crystal River & 12 & 51 & 56 & 47 & \\
\hline & Davis-Besse & 27 & 56 & 82 & 233 & \\
\hline & Diablo Canyon & 0 & 77 & 107 & 86 & \\
\hline & Donald C. Cook & 191 & 176 & 123 & 175 & \\
\hline & Dresden & 116 & 167 & 200 & 345 & \\
\hline & Duane Arnold & 64 & 313 & 145 & 89 & \\
\hline \multirow[t]{7}{*}{$x$} & Fermi & 144 & 285 & 354 & 722 & \\
\hline & Fitzpatrick & 55 & 127 & 81 & 91 & \\
\hline & Forked River & 458 & 304 & 289 & 248 & 1980 \\
\hline & Ft. Calhoun & 112 & 47 & 255 & 233 & \\
\hline & Ft. St. Vrain & 36 & 47 & 205 & 277 & shutdown \\
\hline & Ginna & 126 & 149 & 463 & 295 & \\
\hline & Grand Gulf & 21 & 20 & 15 & 16 & \\
\hline \multirow[t]{4}{*}{$x$} & Haddem Neck & 141 & 249 & 483 & 672 & \\
\hline & Hartsville & 43 & 43 & 68 & 78 & 1982 \\
\hline & Hatch & 20 & 24 & 43 & 36 & \\
\hline & Hope Creek & 14 & 93 & 335 & 370 & \\
\hline \multirow[t]{4}{*}{$x$} & Indian Point & 942 & 793 & 831 & 1534 & \\
\hline & Joseph M. Farley & 21 & 31 & 75 & 53 & \\
\hline & Kewaunee & 13 & 31 & 65 & 85 & \\
\hline & Lacrosse & 15 & 19 & 73 & 57 & retired \\
\hline
\end{tabular}




\begin{tabular}{|c|c|c|c|c|c|c|}
\hline \multirow{2}{*}{$\begin{array}{l}>\text { 500people } \\
\text { per sqm? }\end{array}$} & \multirow[b]{2}{*}{ Reactor } & \multicolumn{4}{|c|}{ people per square mile } & \multirow[b]{2}{*}{ Canceled } \\
\hline & & 0.5 Miles & 0-10 Miles & 0-20 Miles & 0-30 Miles & \\
\hline & LaSalle & 17 & 42 & 75 & 77 & \\
\hline \multirow[t]{4}{*}{$x$} & Limerick & 858 & 564 & 752 & 1281 & \\
\hline & Maine Yankee & 73 & 102 & 84 & 96 & \\
\hline & Marble Hill & 139 & 133 & 307 & 334 & 1985 \\
\hline & McGuire & 15 & 9 & 24 & 32 & \\
\hline $\bar{x}$ & Midland & 537 & 230 & 263 & 168 & 1986 \\
\hline \multirow[t]{17}{*}{$x$} & Millstone & 614 & 382 & 236 & 184 & \\
\hline & Monticello & 142 & 90 & 92 & 189 & \\
\hline & Nine Mile Point & 55 & 127 & 81 & 91 & \\
\hline & North Anna & 29 & 37 & 66 & 77 & \\
\hline & Oconee & 81 & 204 & 129 & 165 & \\
\hline & Oyster Creek & 438 & 320 & 298 & 251 & \\
\hline & Palisades & 68 & 99 & 92 & 83 & \\
\hline & Palo Verde & 10 & 6 & 8 & 11 & \\
\hline & Peach Bottom & 90 & 117 & 295 & 407 & \\
\hline & Pebble Springs & 6 & 2 & 1 & 2 & 1982 \\
\hline & Perkins & 86 & 137 & 240 & 273 & 1982 \\
\hline & Perry & 215 & 220 & 210 & 239 & \\
\hline & Phipps Bend & 75 & 75 & 131 & 130 & 1982 \\
\hline & Pilgrim & 215 & 198 & 200 & 351 & \\
\hline & Point Beach & 14 & 64 & 62 & 71 & \\
\hline & Prairie Island & 50 & 80 & 72 & 143 & \\
\hline & Quad Cities & 39 & 77 & 244 & 148 & \\
\hline \multirow[t]{8}{*}{$x$} & Rancho Seco & 16 & 49 & 254 & 545 & \\
\hline & River Bend & 49 & 71 & 88 & 156 & \\
\hline & Robinson & 155 & 101 & 64 & 82 & \\
\hline & Salem & 14 & 93 & 335 & 370 & \\
\hline & San Onofre & 0 & 0 & 298 & 448 & \\
\hline & Seabrook & 442 & 326 & 318 & 424 & \\
\hline & Sequoyah & 215 & 218 & 304 & 190 & \\
\hline & Shearon Harris & 25 & 76 & 230 & 281 & \\
\hline \multirow[t]{6}{*}{$x$} & Shoreham & 409 & 414 & 506 & 683 & \\
\hline & Skagit & 73 & 68 & 60 & 88 & 1983 \\
\hline & South Texas & 3 & 9 & 27 & 19 & \\
\hline & St. Lucie & 190 & 418 & 200 & 124 & \\
\hline & Surry & 32 & 330 & 280 & 242 & \\
\hline & Susquehanna & 143 & 165 & 276 & 215 & \\
\hline \multirow[t]{9}{*}{$x$} & Three Mile Is. & 444 & 525 & 574 & 430 & \\
\hline & Trojan & 95 & 195 & 100 & 97 & \\
\hline & Turkey Point & 0 & 297 & 385 & 490 & \\
\hline & Vermont Yankee & 124 & 106 & 113 & 97 & \\
\hline & Virgil Summer & 22 & 30 & 91 & 165 & \\
\hline & Vogtle & 5 & 8 & 28 & 116 & \\
\hline & Waterford & 206 & 235 & 294 & 400 & \\
\hline & Watts Bar & 38 & 50 & 66 & 81 & deferred \\
\hline & Wolf Creek & 44 & 15 & 10 & 22 & \\
\hline
\end{tabular}




\begin{tabular}{|c|c|c|c|c|c|c|}
\hline \multirow{2}{*}{$\begin{array}{c}>500 \text { people } \\
\text { per sqm? }\end{array}$} & \multirow[b]{2}{*}{ Reactor } & \multicolumn{4}{|c|}{ people per square mile } & \multirow[b]{2}{*}{ Canceled } \\
\hline & & 0-5 Miles & 0-10 Miles & 0-20 Miles & 0-30 Miles & \\
\hline & WPPSS & 3 & 9 & 85 & 57 & \\
\hline & WPPSS 3,5 & 56 & 49 & 43 & 67 & 1982 \\
\hline & Yankee Rowe & 21 & 65 & 89 & 98 & \\
\hline & Yellow Creek & 4 & 9 & 40 & 37 & 1984 \\
\hline & Zimmer & 70 & 112 & 220 & 424 & 1984 \\
\hline$x$ & Zion & 588 & 721 & 495 & 555 & \\
\hline
\end{tabular}




\section{Distribution List}

\section{U.S. Department of Energy}

Walter F. Pasedag

LWR Safety \& Technology Branch, NE-451

U.S. Department of Energy

19901 Germantown Rd.

Germantown, MD 20585

Sterling Franks, III

LWR Safety \& Technology Branch, NE-451

U.S. Department of Energy

19901 Germantown Rd.

Germantown, MD 20585

Chuck Thompson

LWR Safety \& Technology Branch, NE-451

U.S. Department of Energy

19901 Germantown Rd.

Germantown, MD 20585

Steven Sorrel

U.S. Department of Energy

Idaho Operations Office

VIA POUCH MAIL

\section{Nuclear Regulatory Commission}

Bill Morris, NRC - RES

Leonard Soffer, NRC-RES

Charles, Miller, NRC - NRR

Falk Kantor, NRC - NRR

Robert Erickson, NRC - NRR

\section{Other Organizations}

Ninu Kaushal

CECo

1400 Opus Place, Suite 650

Downers Grove, IL 60515
Mike Wallace

CECo

1400 Opus Place, Suite 650

Downers Grove, IL 60515

Susan Gray

EPRI

3410 Hillview Avenue

P.O. Box 10412

Palo Alto, CA 94303

Joe Santucci

EPRI

3410 Hillview Avenue

P.O. Box 10412

Palo Alto, CA 94303

John Ronafalvy

NEI

1776 Eye Street NW, Suite 300

Washington, DC 20006-3706

John Schmitt

NEI

1776 - Eye St., NW

Washington, D.C. 20006-3706

Tom Tipton

NEI

1776 Eye Street NW, Suite 300

Washington, DC 20006-3706

David E. W. Leaver

Polestar Applied Technology, Inc.

4 Main Street

Los Altos, CA 94022

Tom Crimmins

PSE\&G

80 Park Plaza, T11A

Newark, NJ 07101 
Lou Long

SEI

P.O. Box 1295

Birmingham, AL 35201-1295

Stephen Additon

TENERA, LP.

1901 Research Blvd.

Suite 100

Rockville, MD 20850-3164

T. G. Theofanous

Center for Risk Studies \& Safety

UCSB

6740 Cortona Dr.

Goleta, CA 93117

\section{Sandia Internal}

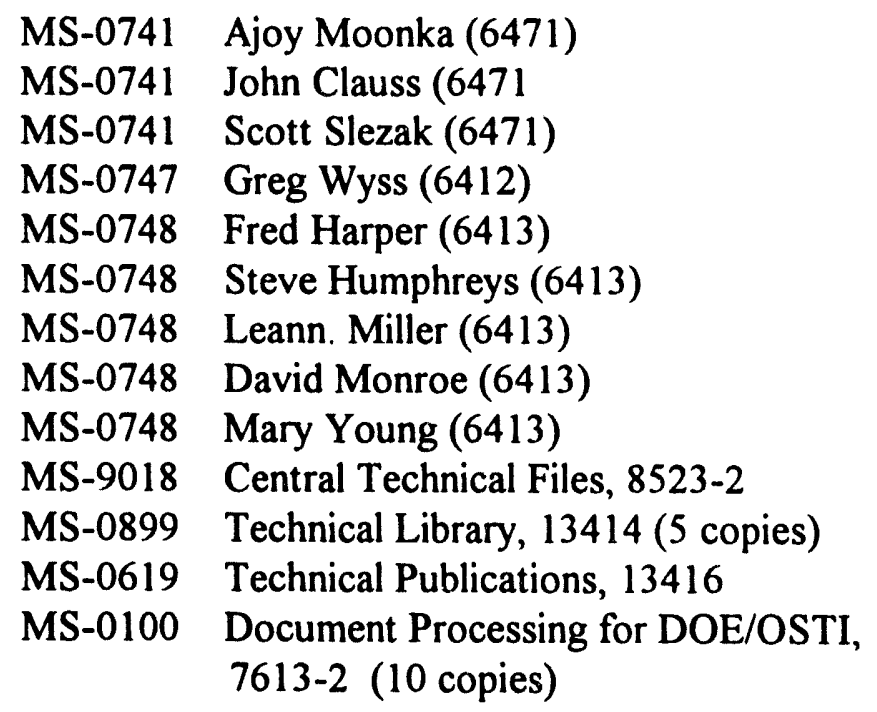



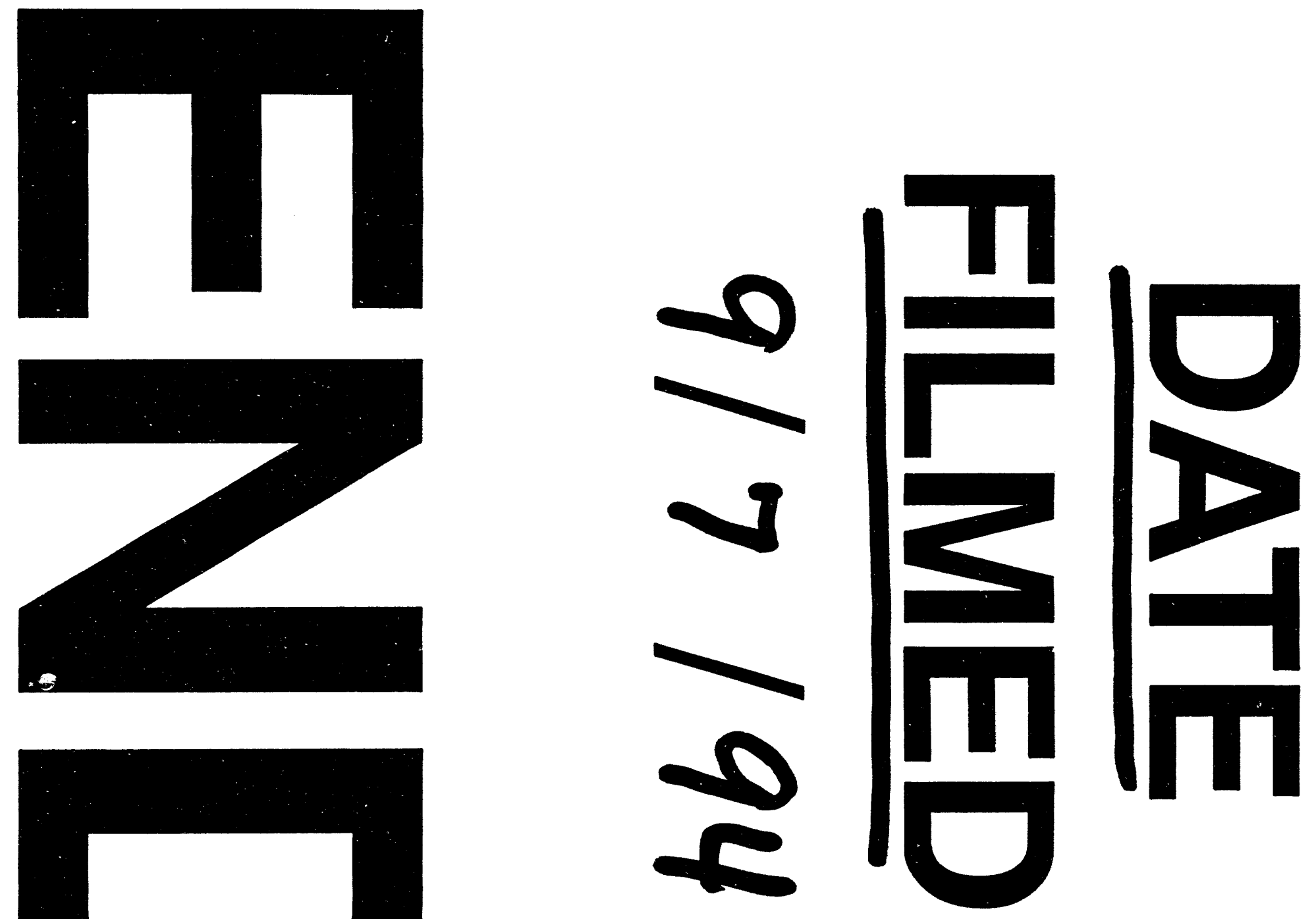
i...

- 